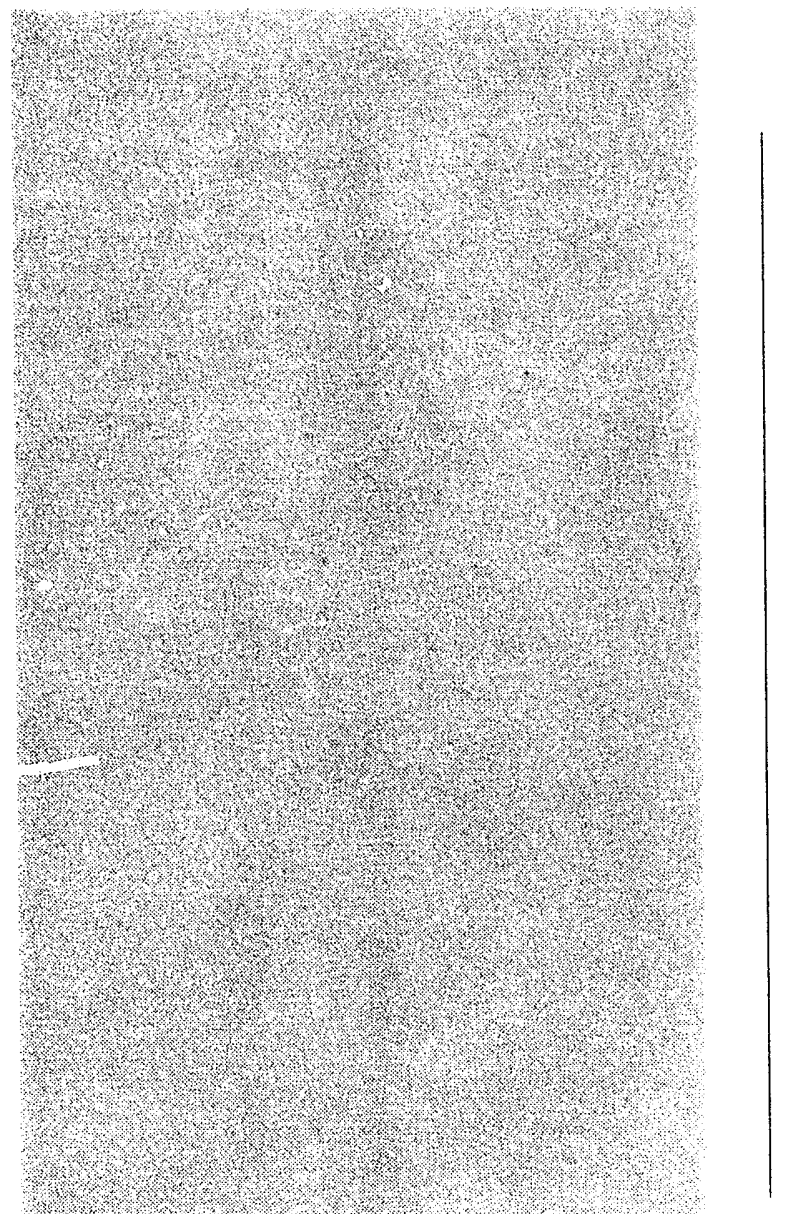

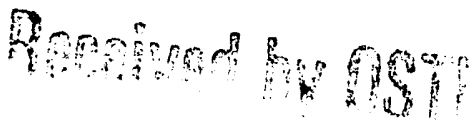

$$
\begin{aligned}
& 0610.099
\end{aligned}
$$

\title{
Migration to a Distributed System Architecture at the National Test Bed
}

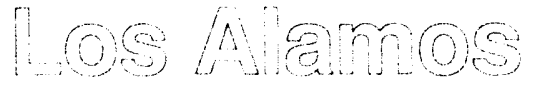

Los Alamos National laburatory is operated by the Unioersity of California for the United States Department of Energy under contract W-7405-ENG-36. 
An Affirmative Action/Equal Opportunity Employer

This report was prepared as an account of work spom... d by an agency of the

United States Government. Neither The Regents of the Unizersity of California, the

United States Government nor any agency thereof, nor any of the ir employee's, make's any warranty, express or implied, or assumes any legal liability or responsibility for the accuracy. completeness, or usefulness of any information, apparatus, product, or process disclosed, or represents that its use would not infringe privately owned rights. Reference herein to any specific commercial product, process, or service by trade name, trademark, mamufacturer, or othe'ra'se', does not necessarily constitute or imply its endorsement, recommendation, or facoring by The Regents of the University of California, the United States Government, or any agency there'of. The ziews and opinions of authors expressed herein do not necessarily state or reflect those' of The Re'gents of the University of California, the United States Govermment, or any agency thereof. 
LA- -12054-MS

DE92 000805

Migration to a Distributed System Architecture at the National Test Bed

Randy Hoebelheinrich

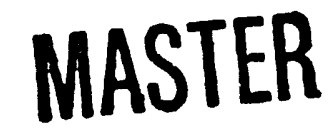

DISTRIBUTION OF THIS DOCUMENT IS UNLIMITED

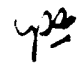

ப(O) $S$ S 


\title{
MIGRATION TO A DISTRIBUTED SYSTEM ARCHITECTURE AT THE NATIONAL TEST BED
}

\author{
b $\mathbf{y}$
}

Randy Hoebelheinrich

\begin{abstract}
This is a study to consider the mission of the Strategic Defense Initiative Organization's National Test Bed (NTB) and the current directions of gigabit networking and distributed computing research and to produce a report describing a 5- to 10-year vision of an NTB computing architecture and migration path to that architecture.
\end{abstract}

\section{Introduction}

This report is the result of investigations in the literature and experience in the ficlds of distribuicd systems, high-performance computing, and gigabit networking. One is struck by the volume and variety of research and development in these areas. One is also reminded of the model of change by Thomas Kuhn. 1 In this model, we see three stages of change. In the first stage, there is no standard way to do something. There are only competing models with duplication. Current work in distributed operating systems is an example. In. the second stage, a standard exists and efforts focus on more specific details of the model. The very mature study of Ethernet is an cxample. The third stage is the revolutionary step. In this stage, inadequacies appear in the model. One group of people attempts to extend and improve the model while a minority of others take a fresh approach by stepping back, looking at fundamentals, and producing a new model to match $n: w$ requirements. The best example in the current context is high-speed protocols. It would secm we are currently well into Stage 3, if not Stage 1, of a computing technology revolution. This report suggests a distributed system architecture of the near future implementing various methods, mechanisms, hardware, and software from the previously mentioned ficlds. No pretense is made that this is the wave of the future or the only way to procecd. It is intended to stimulate thought, discourse, and, hopefully, action to realize the potential the next generation of computing holds for cveryone.

The outline of this report is as follows: Section 1 provides the charter and goals of the report. Section 2 provides some background and configuration information on the National Test Bed (NTB), its requirements, and a reference to a system description 
document. Section 3 discusses current progress in distributed gigabit networking including issues, a brief discussion of the literature, and test bed projects planned or in progress. Section 4 will describe a proposed NTB distributed system architccture. Section 5 will describe a migration path to that architccture. Scction 6 lists rescarch initiatives to help facilitate that migration. Sections 7 and 8 provide a summary and conclusion.

\section{Charter}

The charter for this study is to consider the mission of the NTB and the current directions of gigabit networking and distributed-computing rescarch and to produce a report describing a 5- to 10-year vision of an NTB computing architccturc and migration path to that architccture.

\subsection{Goals}

The goals for this report include the following items.

1) Compile background references for future discussions of an NTB architecture.

2) Describe a distributed system architecture (DSA) for the NTB.

3) Describe a migration path to that DSA.

4) List crucial research initiatives needed to realize that DSA.

\subsection{NTB Background and Configuration Information}

Information in this section is general in nature and a result of discussions with members of the NTB, the Strategic Defense Initiative Organization (SDIO), NTB users and a study of the System Description Document NTB-242/442-(0)6. 2

\subsection{Strategic Defense Initiative}

The Strategic Defense Initiative is a program to produce a defense from ballistic missile attack. The program is administered by SDIO in the Pentagon. A significant portion of the program is dedicated to computer simulation of defensive technologies and threats to specify a Strategic Defense System (SDS) architecture integrating these technologies into a defensive shield.

The SDS architecture consists of some combination of platforms. Components such as weapons systems, sensors, communications, and balle managers combine to form a platform. For example, a platform may have a real weapon system with its associated sensor, battle manager, and communication unit at the same location in space, on the ground, or in the sea. Platforms grouped together form either a blue defensive or red 
offensive capability. Both offensive and defensive platforms make up the SDS and this architecture is, by definition, of global extent.

Selection of the appropriate combination of platforms and components on those platforms is not an obvious process. New technologies are being explored and tested. Integration of these technologies into a real working system is expensive in terms of time, money, and effort. Simulations of individual and interacting systems provide a far more reasonable environment for testing. SDIO created the NTB to provide this simulation environment.

\subsection{National Test Bed}

The NTB was established to test and analyze instances of system architectures for the SDS. The NTB is made up of a set of computing rescarch sites. These sites are geographically distributed, represent various organizations, and focus on specific systems proposed for the SDS. Computing communication is currently accomplished with satellite and terrestrial links. The topology is a star. The National Test Facility (NTF), located at Falcon Air Force Base near Colorado Springs, is one of these sitcs. It acts as the control and coordination site for NTB experiments sponsored by SDIO. Figure 1 shows the configuration of an extended Local Area Network (LAN) at the NTF.

\subsection{National Test Facility}

The NTF acts as the heart of the NTB configuration. It is a major computing and simulation facility for development and execution of SDIO-sponsored simulation programs in the NTB network. It is responsible for simulation experiments from design 10 final analysis. There are currently several simulation programs of varying capabilities resident at the NTF. Data for simulations, including threat, cnvironment, parameter, and scenario information, are kept at the NTF. The computer network and communication framework are constructed from commercial LAN, High-Specd Local Network, bridging, routing, and fiber-optic equipment. The NTF is essentially an extended LAN constructed from bridges and passive star couplers. This configuration will be discussed further in Section 5. NTB users access the NTF network cither on site or through remote access set (RAS) equipment.

\section{$2+$ Remote Access Sot Sites}

NTB users are located at sites geographically distributed around the NTF. These siles are known as Special Program Offices (SPOs) or elements. An SPO is a contractor 


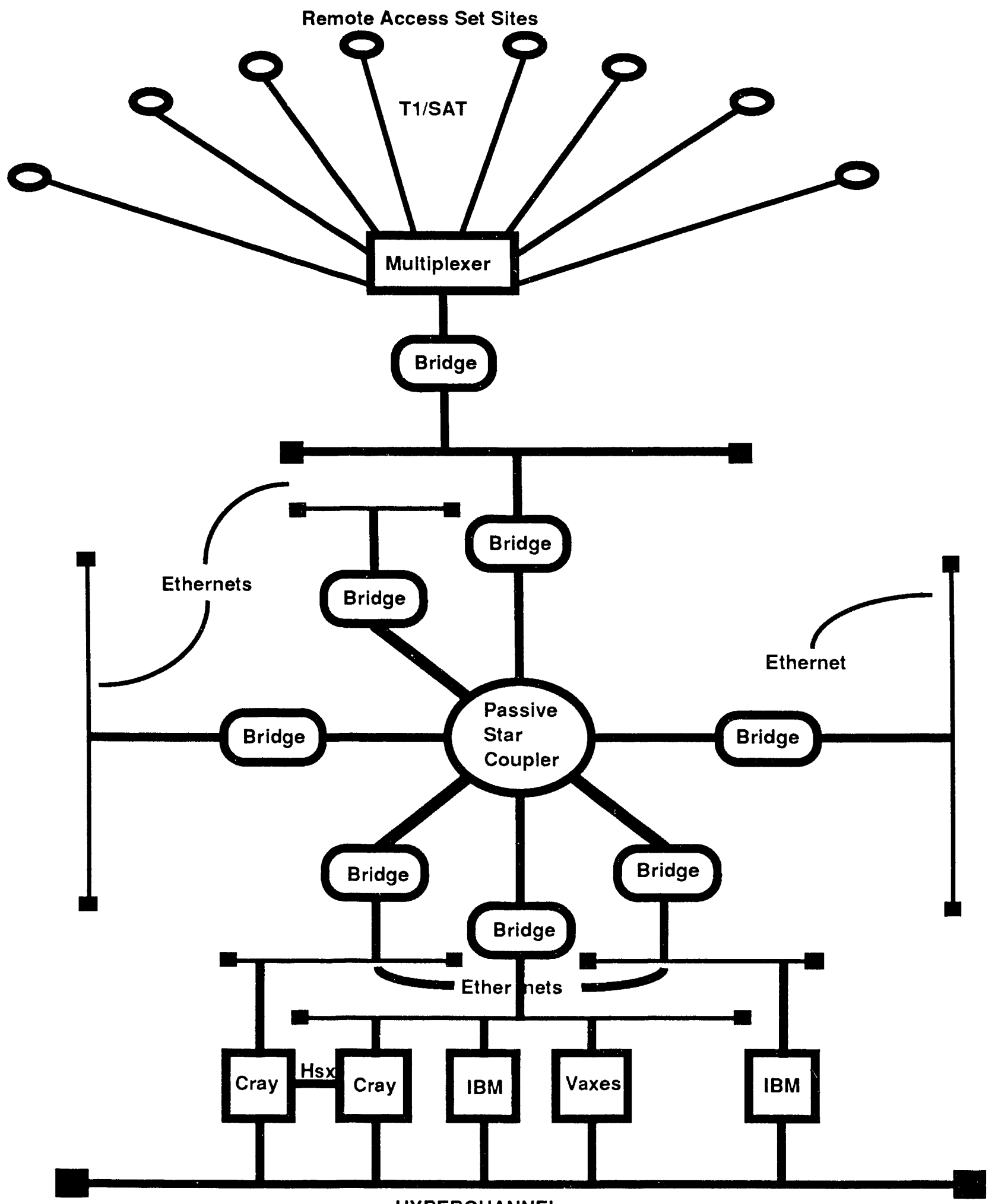

HYPERCHANNEL

Figure 1. Extended LAN at the Network Test Facility. 
responsible for building a specific piece of hardware or component of the SDS. The SPO is also responsible for providing a computer model of the component to the NTB for testing and integration into the SDS.

The RAS provides an SPO computing access to NTB resources, specifically the NTF. A RAS consists of a set of equipment including two workstations, a disk, a tape drive, a printer, communication and encryption equipment, a network interface unit, and a LAN. The LANs are Ethernets using the Institute of Electrical and Electronic Enginecrs' (IEEE) 802.3, 802.2, and the Defense Data Network's Transmission Control and Internet (TCP/IP) protocols. Network routers connect SPO LANs to the RAS node.

\subsection{NTB Requirements}

The mission of the NTB is to exccute geographically distributed supcrcomputing simulations. These distributed simulations run on multiple mainframes at various sites. A stated requirement is to be able to run a distributed simulation with dedicated links for up to 36 hours without interruption. At the same time, the usual science and enginecring development should also receive sufficient resources on the same mainframes.

Other computing requirements at the NTB include the usual set of items such as reliability, performance, development tools, and a straightforward user interface. Management, status, auditing, and accounting are also required by administrative users. Two additional requirements stand out from all the rest. These are security and communication latency. Because this is a defense program of strategic importance, cvery precaution is necessary to safeguard information at the NTB. This is an especially challenging problem because of the wide area extent, number of organizations, and planned multinational membership of the NTB. Issues of link encryption, data storage, compartments, partitions, necd-to-know separation, and multilevel secure systems are necessary topics for later discussion. For further details, refer to the NTB INFOSEC Security Strategy Working Paper-6962 published by Mitre. 3

Latency in distributed simulations is another challenge. This is a requirement that will be dealt with at many fronts including the communication framework, system efficiency, and application algorithms. For purposes of this report, the first two will be dealt with in some detail. Application algorithms are left for another cffort. 


\subsection{NTB Architecture}

Further details, such as main frame equipment, communication equipment, and layout, can be obtained by revicwing the System Description Document NTB-242/442006. 2

\subsection{High Performance Computing}

The past 10 years have scen a rush of reports, pancl discussions, and calls for new initiatives in the area of high-performance computing. Congressional inquirics and opportunitics made possible with new technology have prompted these efforts. The Federal Coordination Council on Science, Enginecring and Technology, in response to Congress, had also recommended that expert panels assess necds and activitics in high-performance computing. The reason can be summed up as cconomic motivation. The potential progress in science, enginecring, and industry is clcar. Modeling and simulation, in close association with theory and experiment, act as the third member of scientific research. 4 Benefits include insight, fecdback, and cost savings. Even though rapid development has occurred, the consensus is that far more needs to be done. For example, a call for a national initiative costing on the order of $\$ 1.5$ billion over a 5-year period has been made. Background information on these reports can be found in References 4 and 5 .

Recommendations from panels for a national computing initiative 4 covered threc arcas including applications, advanced systems, and parallel computing. Pancls of these areas agreed that access to a national gigabit network was crucial to organizing distributed supercomputing into an integrated, coherent systers. Recommendations from another gigabit-working group 5 focused specifically on national highperformance or gigabit networking.

High-performance computing encompasses applications, system softwarc, and a transport network to provide information transfer. The necessity for a network framework is a critical first step for the support of communicating applications and distributed simulations. For purposes of this report, further discussions will concentrate on the network framework, supporting protocols, and system software. This will establish the necessary basis for the goal of a DSA as proposed in Section 1.2.

\subsection{Distributed Gigabit Networking}

A number of workshops and ad hoc working groups have produced reports and recommendations concerning issues, architectures, protocols, and related system software for very high-speed networks. Two good examples of these reports can be 
found in References 5 and 6 . They provide excellent food for thought on issues and the revolutionary stage of networking in which we find ourselves.

\subsection{Recent Efforts}

The National Science Foundation's National Supercomputing Centers were implemented after 1985 following the Lax Report 7 and later the Bardon-Curtis Report 8 recommending research, development, design, and implementation of new supercomputing systems. A number of these centers now exist across the country. A list of current research and development activities related to gigabit networking can be also be found in Appendix A of RFC 1077. 5 Since that list was compiled progress has continued. For example, the Corporation for National Rescarch Initiatives is coordinating a gigabit test bed research program with results contributing to rescarch needed for the proposed National Rescarch and Education Network. Five test beds are proposed for installation during 1990. 9 These test beds include academic, industrial, and national laboratory collaborations. This program is slated to research issucs in wide area networking (WAN), metropolitan arca networking (MAN), highspeed protocols, switching, optics, systems software, and sccurity among others. A brief overvicw of each of these test beds will be discussed in a later section. This next section will describe major issues of gigabit networking.

\section{$\mathbf{3 . 1}, 2$ Issues}

The threc most notable issues in a distributed gigabit environment are the impact and extent of parallelism, distribution at all levels, and integration of hetcrogeneous systems. Parallelism is the answer to increased necds in performance at all levels including applications, system architectures, protocol structures, switching, and transmission medium. Distribution aids parallelism and provides for better sharing of capital intensive resources and access to specialized processing needs. Given the hetcrogencous nature of specialized systems, integration of the elements into a single system with a uniform user and $I / O$ interface is necessary. 10-15 Thus, the mainframe, workstations, disk farms, graphics stations, and specialized devices will be integrated to form a logical single distributed computer managed by a single distributed operating system. This has becn referred to as the metacomputer. 14 See Figure 2 for a conceptual view. We begin to sec the network as a backplane. or resource, of a larger sjstem or metacomputer witich also includes hosts as special purpose devices or peripherals. These hosts are no longer autonomous but components of a larger system. The NTB's SDS is representative of this larger system. 
This distributed simulation architecture and environment abstractly mirror the real world system of the entire globe and surrounding space populated with subsystems, or platforms. We now discuss the overali architecture breaking it down into hardware, controlling software, and service characteristics.

\subsubsection{Hardware Issues}

The primary hardware issue in the ncar future will be consideration of fiberoptic technology and all of its ramifications. This includes switches, interfaces, holographic memory, multiplexing methods, and standards. Another more immediate hardware issue is incorporation of fast packet switches into the network fabric. By far, the most immediate, critical issue facing commercial computer vendors is the impact of massively parallel processing and communication on the architecture of their mainframes, workstations, and devices. These systems can no longer act as autonomous entities that happen to have $\mathrm{I} / \mathrm{O}$ devices to communicate with others. An abstract uniform interface is desirable. Their architectures would best be served by opening up and developing a multiprocessor/multicomputer frame of reference.

Growth and cvolution is a ccrtainty in computing networks. Hardwarc components such as switches, backplanes, and, especially, mainframes are best designed to be modular, scalable, and extensible. Something of the characteristics of crystal morphology and the flexibility of a Tinkertoy set is uscful. Modular construction of a network, as the need dictates, helps in managing and maintaining such a potentially complex system. Scalability allows growth without undue impact on the currently existing structure. Scalability is also a function of link and switch discipline. Examples are the networks assembled with point-to-point links or a shared broadcast medium like Ethernet. Extending the Ethernet network into a hicrarchy is possible but not casy. In a parallel environment, significant help can be gained by the use of richly connected hardware not inherently restricted to one dimension or sequential access. A structured topology, rather than an ad hoc amorphous conglomeration of equipment, lends itself to better understanding and management of the network framework. Extensibility through flexibility is also a neccssary quality, for, without a plan and carried too far, extending a network becomes chaotic and virtually unmanageable.

Finally, both switches and interface adaptors present challenges in a gigabit environment because they will be temporary boltlenecks for gigabit fiber-based networks. They do have, however, the most potential for contribution to network backplane sinplicity. Protocol implementations in silicon are also expected to 
contribute to better performance in switches and interfaces. Photonic wave division multiplexing (WDM) and frequency division multiplexing also play in the picture of simplicity in a network backplane.

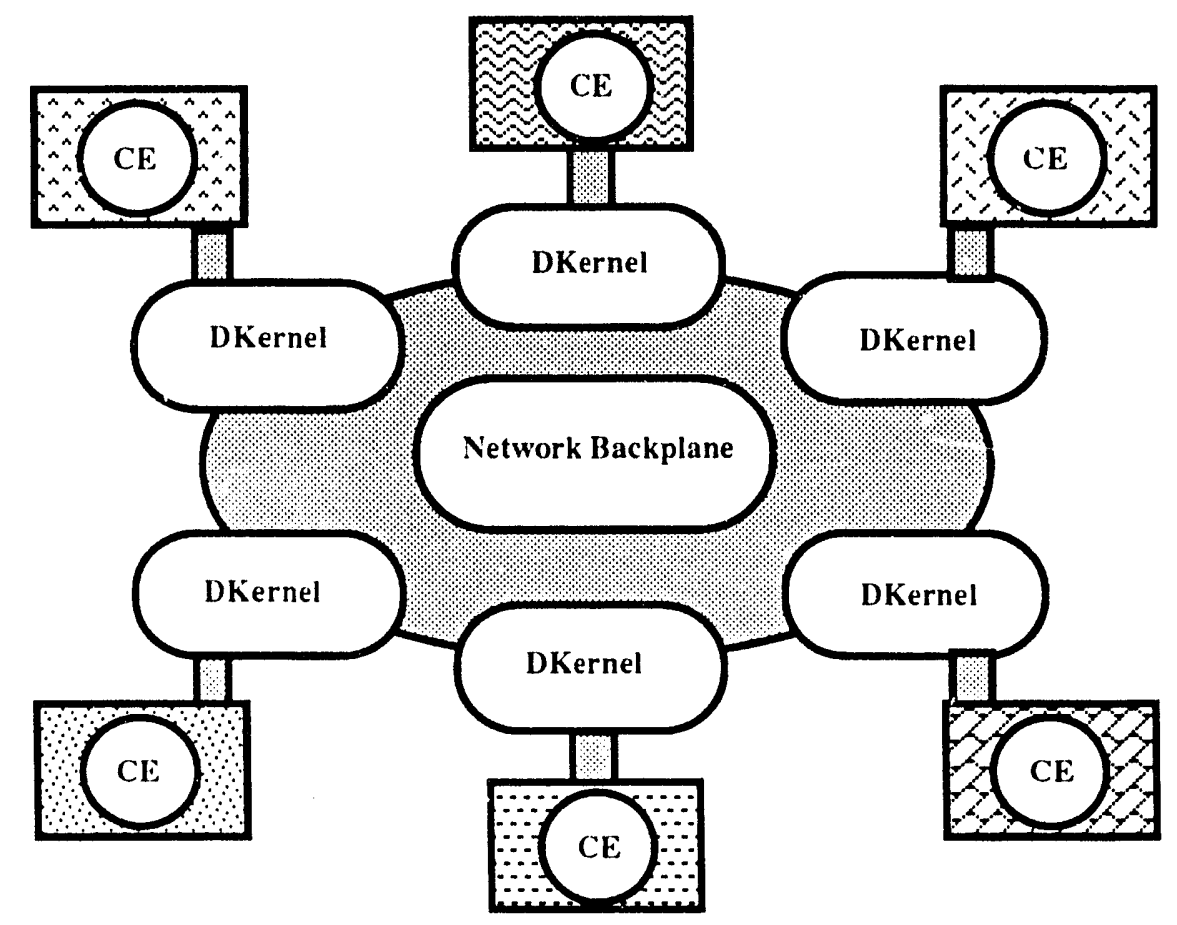

Figure 2. Conceptual view of a metacomputer.

\section{$\mathbf{3 , 1 , 2 , 2}$ Software Issues}

The most critical issue, from a software perspective, is the operating system bottleneck in a gigabit environment. This again is actually a part of the greater issue of architccture. From the software standpoint, if we step back and realize that we'll eventually be dealing with and cvolving to an integrated entity, we can no longer think of opcrating systems on hosts using network communication scrvices as a loosely related collection of functions and policy for communication between a multitude of autonomous objects. The software for this system is no longer a communication tool between pecrs. The various operating systems and network functions end up being a distributed operating system managing all resources such as the backplane (network), the peripherals (hosts and devices), data storage (mass storage), and user access (concentrator terminal front ends). In this way, we move from a set of hosts with their own autonomous opcrating systems to a single opcrating system. 12,13 
Important elements of software are the protocol for data transmission, interfaces to the system software, the system operating, or managing, software itself, and the services provided. The use of interfaces and layering necds to be explored and expanded as an avenue for cooperation and integration of these clements into a synergistic system which would otherwise be unattainable. 5,16-17

Another fundamental and challenging problem within the distributed system will be management of simultancous pairwise transmissions. Virtual circuits have been the traditional mechanism up to now. A very promising variation of this will be the use of WDM with its extremely high capacity for channel assignments to uscrs. It may very well be a natural choice for switching data as the technology reaches maturity. Many technological barriers currently exist, however.

\section{$\mathbf{3 . 2 . 3}$ Service Issues}

Services exist to identify, locate, allocate, protect. maintain, and manage the use of objects in this system. Naming, addressing, and routing serve to identify and locate objects. A directory service acts as the clcaring house for registration of an entity's identity, location, and characteristics or capabilitics. By carcful selection and assignment of namespace, necd-to-know scparation, partitioning, and general access control can be exercised over users of system resources. Once location and access have been established, other services aid in rescrving bandwidth, minimizing delay, and managing faults and crrors as well as traffic management such as flow and congestion control or redundant and alternate routing.

Security deserves special notice here. In the past, security has been largely ignored in opcrating systems. In a distributed system, security will be an absolutc requirement to maintain the integrity of the system within itsclf. It will be necessary for resource allocation, protection from accidental or malicious activitics, and even maintenance by temporarily limiting access to objects. Security, unlike in the past, will be an implicit part of the system infrastructure by requiring registration, allocation, and authentication of objects with a necd to communicate or interact in any normal way with rther objects. This would be accomplished by association of objects into a logical set by means of dynamic logical addressing. Logical group membership can then be determined at the entrance and exit of the network. This provides separation at the host level. The final separation is achicved for transaction protection by use of subsets of logical addressing as well as key and encryption separation as specified by communities of interest (COI) in Reference 3. COIs, logical addressing, and the directory service provide an integrated security 
structure for the DSA. Multilevel secure (MLS) systems are critical and need investigation into their relation to a distributed operating system environment. MLSs are outside of the scope of this report.

\section{1 .2 .4 Complexity Issues}

Gigabit networking will force one to review, and in many cases rethink, the solutions and methods successful in past network technology. Time becomes much more critical. For example, consider the volume of potential data transferred from onc or more sources during retransmissions, acknowledgements, connection setup, context switching, data copics, reassembly and disasscmbly of messages, buffering, store and forward switching, overhead from administrative protocols like the Routing Information Protocol (RIP), sequential access of the LAN media such as a bus, and the media access routine itself. One then realizes, you cannot afford to have such an impact on data transfers and, consequently, application software because of mechanisms successful in the past. A much more efficient, simple, and natural approach is in order. Piccewise integration and explicit or ad hoc methods of network management suddenly seem futile and woefully inadequate in the context of gigabit cnvironments. Explicit manipulation of data transfers becomes complex and awkward. Networks dealt with as complex, dynamic, and physical systems utilizing implicit characteristics of management from sclf-organizing phenomena scem far more elegant and effective as a means of providing data transfer and management scrvices. $18-20$

As an example, consider flow and congestion control of data. Back pressure has been used as a method of flow control. 21 Thinking of the network backplane as a fluid pipe, one can visualize messages backing up 10 a number of sources. The latency of flow information back to a source is a function of the elasticity of buffers and return flow signaling. 22,23 This is a considerably shorter period of time than cxplicit control through windowing methods for flow control and source quench of message flow from the source for congestion. Windowing scems artificial compared with the use of back pressure which takes advantage of information passing implicitly through the system itsclf. Cars in frecway traffic provide an excellent analogy of flow control. For congestion, dumping packets is another artificial method that in fact defcats the system by blecding off pressure that can act as fecdback information to sources at the entrance of the network. 


\subsection{Interconnection Network}

The network is the major resource of a distributed system. 24 As the communication resource between processors, menory, and devices, this resource, or Interconnection Network (IN), has received considerable attention in the litcrature. Primary arcas of concentration include the switching method, network topology, mode of operation, control stratrgy, and the transport medium used. The IN can use a shared medium, shared memory, or a crossbar switch. The IN can also use a multistage switch made up of component switches of buses, shared memory, or crossbars.

The actual communication between processors is accomplished with cither message passing or shared memory. Message passing is the most common and best understood method. Shared memory is flexible but has expensive overhead in terms of hardwarc implementation and cache coherence algorithms to maintain a consistent vicw of data in memory for all processors. A short comparison of the pros and cons of shared memory vs. message passing is in Reference 25. Message passing in multicomputer networks is discussed in References 26 and 27.

Finally, crossing the network is only part of the story. Moving data into and out of a host constitutes a significant portion of transport latency. Anyone who has traveled to and from airports should have some sympathy for this problem. Work in the area of network adaptors and network access is a rapidly growing area of rescarch particularly in light of the growing interest in distributed systems and gigabit networking. For good cxamples refer to References 22 and 28.

Transport media, switches, and network adaptors make up the hardware portion of IN technology. Understanding the INs themselves is important because of their potential for fault management. Due to the sheer volume of literature on switch and network adaptor stratcgies, this section will largely serve as a bricf introduction and point the interested reader to other sources for detailed descriptions. Very good surveys of interconnection networks can be found in References 29-32. Two good sources of information on high-performance switching techniques can be found in References 33 and 34 . A survey of Very Large-Scale Integration (VLSI) implementations of protocols is found in Reference 35.

\subsubsection{Transport and Storage Medium}

Fiber, coaxial cable, parallel copper cable, and shared memory are examples of the transport media available for communication. It is well known that it is only a matter of research, time, and effort before fiber will be the mainstay medium of choice. 
Interesting work is also being done in optic holographic memory ${ }^{*}$ and optical disks. For architectural issues in photonic networks refer to Reference 36 . Buffer and storage device work is being done with video random access memory (VRAM) for pipeline protocol processing and content addressable memory (CAM). The most notable issue concerning physical layer entities is limited availability of highperformance standards necessary for supercompuing data transfers at gigabit rates. This becomes an extremely important issue when considering connectivity to commercial supercomputers. The Synchronous Optical Network (SONET) is a physical protocol currently receiving widespread interest especially by the telecommunications industry. It docs not casily interface to commercial supercomputers. As will be evident later, the High-Performance Parallel interface (HIPPI), 37 a proposed ANSI standard, is being proposed in many projects to fill this necd.

\section{1 .32 Switching}

Most people are used to the packet switching of Ethernet even though they may not think of it as a switch. The switching is passive and done by a distributed method of packet recognition. Traditional packet switching has becn done on general purpose computers programmed for a special purpose. With progress in VLSI technology and the ever-increasing need of applications for greater performance, a new generation of switches has been developed. These switches are known as fast packet switches. They take advantage of distributed control and parallelism by moving the intelligence for packet control to the link or channel level and communicating with cach other over various possible internal interconnection network backplanes. Notice the similarity to the interconnection network of the gigabit network itself. By generalizing this equivalence, you can consider hosts, clusters of hosts, and networks of clusters identical entitics from a system software standpoint. This point will be claborated further in Section 4.

Switching falls into the two catcgorics of packet and circuit switching. Advantages and disadvantages exist for cach technique. The traditional method of gaining the advantages of both is called the virtual circuit. Other more recent methods are described in References 38 and 39. These methods describe switching and data transport scrvices that combine characteristics of both packet and circuit

\footnotetext{
* This information was presented at Frontiers of Supcrcomputing II: A National Reassessment, Los Alamos National Laboratory, Los Alamos, New Mexico, August 1990.
} 
switching. Examples include virtual cut through, wormhole and circuit staging methods. Ideally, an evolution to a scrvice providing a continuum betwecn full circuit and packet transfers at the physical level will provide the simplest and most flexible data transfer service.

\subsubsection{Multistage Switches}

The largest class of switch types are the spaced divisien switches. These include multistage interconnection networks (MINs) such as banyan and delta networks, crossbars, and disjoint path switches. The MIN work has been the resiult of research in telecommunications. 33 They are noteworthy for the use of self routing and the ability to take advantage of the fault tolcrant characteristics of a regular topology. Fast packet switches of this design include the Starlite 40 and one by Turner. 41 One of the critical issues of designing a switch is where to do the buffering of data while a physical connection is cstablished. The three choices include input, internal, and output queues. The preferable choice is output queucing. 42 This design feature has been incorporated into at least two switches of the disjoint path type including the Knockout 43 and Integrated Switch Fabric. 44

\section{1,3.2.2 Crossbar Switches}

Crossbar switches have always becn popular because they are internally nonblocking. They are, however, subject to concern about placement of buffer queues, extcrnal blocking, and exponential growth in crosspoint hardware. Crossbar switches with associated interfaces have recently been implemented at Los Alamos National Laboratory (LANL) and as commercial products by Network Systems Corporation and Ancor Communications. Today these commercial products provide supcrcomputer connectivity using HIPPI.

\section{3.2.3 Shared Memory Switches}

Shared memory fast packet switches are also being built. Work on shared memory communication networks can be found in References 45-47. These switches are characterized by all input lines fecding data into a single input stream for storage and subsequent transfer to the correct output line. The Prelude switch is an example of this type. A good description can be found in Reference 48. NASA has installed a memory-based network designed and built by two commercial firms. 49 


\subsection{Shared Medium Switches}

The shared medium switch is similar to the shared memory switch in this respect and has becn realized in the design of the SCPS, 50 ATOM, 51 and PARIS switches. 52

\section{3 .25 Bus Switching}

To deal with the increased call for performance, multiple-bus architectures are also receiving considerable attention. Ultra Network Technologics probably has the best example of a commercial switching product using this type of architecture. The multiple-bus architecture is surveyed in Reference 53.

\section{1 .3 .2 .6 Optical Switching}

Finally, one must consider optical switching and networks. Optical crossbars, interconnection networks, and switching with WDM are particularly interesting to industry as an integrated framework for voice, video, and data transmissions. Optical switching and networking topies are discussed in References 36 and 54-58.

\subsubsection{Network Interface Adaptors}

Network interfaces 10 hosts and fast packet switches are also under investigation. They serve two purposes. They provide access to the internal backplane of the host and acess to the network transport media, which, as we have stated, is another backplanc. Interfaces on switches are really no different. Again, we can sec the equivalence when we consider that no matter where an interface is located its fundamental purpose is to move data over a transport backplane. The other purpose is to Iranslate between dissimilar backplanes. Related responsibilitics include buffering, address translations, routing, flow cont sl, security, and other protocol functionality up to and including internet gateway translations. At some point, the network adaptor will cvolve into a communication coprocessor, or pecr, in a multiprocessor cnvironment. This is already evident in the iWarp 59 implementation of nodes with computation and communication processors.

A number of network interface araptors have been built. One is the Communication Accelerator Board (CAB) in Carnegic Mellon University's (CMU) Nectar Network. 22 It processes protocols up to the transport level. Another wellknown adaptor designed and built at Stanford for the Versatile Message Transport Protocol (VMTP) is the Network Adaptor Board. 28 This protocol will be discussed in the next section. The original CrossBar Interface (CBI) 60 is a HIPPI-based protocol processor built in a collaborative cflort by LANL and Digital Equipment Corporation 
(DEC). It processes protocols at the local network layer and expects the host to handle the transport and internet layers. A commercial adaptor has been built by Ultra Network Technologies. It is designed with a flow-through architecture for protocol processing. It processes a variation of the International Standards Organization's (ISO) Transport Protocol Level 4 (TP4) transport and Connectionless Network Protocol (CLNP) protocols or TCP/IP. The final adaptor mentioned here is designed to process the Xpress Transfer Protocol (XTP) 39 of Protocol Engines. XTP was designed by Greg Chesson and is a pipeline protocol combining the network and transport layers into what is called the transfer layer.

\subsubsection{High-Performance Protocols}

High-performance protocols can be classified into two groups at this point in time. The first is existing protocols that are being worked with to improve implementations and extended to meet new requirements. This includes TCP/IP and TP4/CLNP. The other is the group of new protocols designed with very high performance in mind. These include VMTP, 61 XTP, 39 Network Block Transfer (NETBLT), 62 Asynchronous Transfer Mode (ATM), 63 Switched Multi-Megabit Data Service (SMDS), 64 Frame-Relay, 65 and the Scalable Coherent Interface (SCI). 66,67 A continuing debate exists over the comparative advantages and disadvantages of the groups. The reader is reminded of the discussion on change presented in the introduction of this report. Since the characteristics of TCP/lP are fairly well known, attention here will concentrate on a $\mathrm{few}$ key issues regarding the latter group.

Other interesting protocol issues, such as packet switching as opposed to circuit switching or us of source routing, are discussed in References. 68-70 Performance and latency are the overwhelming concerns of newer protocols. Improvements include the use of virtual cut through routing, 71 wormhole routing, 72 sclf routing, 73 and alternatives to retransmissions and the use of fecdback mechanisms for flow control. Another weakness with current protocols is the lack of cooperation between layers of protocols for passing uscful information, such as notification of crrors and congestion. $5,16,17$ It is also possible to reduce data copying by providing pointers to memory for appropriate placement of data as it is read in from the network. 22,74 A broadened set of services, such as carrying voice, video, and data, are new requirements over the past. Additional flexibility to existing services, by including the advantages of both packet and circuit switching, is also an issuc. 


\subsection{High-Performance Transport Protocols}

VMTP is a transport protocol designed for transaction communication and remote procedure calls (RPC). NETBLT is another transport protocol designed for transfer of large blocks of data. Transport protocols are of interest here because of their relation to the lower network framework protocols optimized for high-specd network communication such as ATM.

XTP is designed for VLSI and works in a pipeline fashion so as to complete processing of a header in a packet's arrival time. It also combines packet and connection services to take advantage of both types of data transfer.

\subsubsection{High-Performance Framework Protocols}

ATM is the telccommunication industry's version of a packet-switching protocol. Traditionally a circuit-based industry, ATM uses 53-bytc packets with virtual path and virtual channel identificrs to implement virtual circuits. One hurdle for this protocol is packet assembly/disassembiy, which is a related issue to fragmentation of datagrams. Fragmentation has recently come under scrutiny for performance reasons. 75

The Fiber Distributed Data Interface (FDDI) protocol is currently available and cxpected to act as the follow-on to Ethernet and will be the mainstay protocol for LANs of the near future. It is a specification for the physical and media access layers of a token-passing ring. At $100 \mathrm{Mbit} / \mathrm{s}$, it is an order of magnitude increase in bandwidth over Ethernct.

SMDS is actually a public packet switched data service rather tian a protocol and expected 10 be offered in 1991. It acts as a subnctwork communication framework providing packet communications between LANs, computers, and workstations. The actual network providing SMDS is transparent to all users and only visible at the network interface as the SMDS Interface Protocol (SIP). SIP is divided into threc protocol laycrs for addressing, framing, and transport cquivalent to a media access control (MAC) and physical layer protocols. Currently, these levels are based on the Distributed Queue Dual Bus MAC protocol defined in IEEE 802.6, and physical signal specds of 1.544 (DS1) to 44.736 (DS3) megabits per sccond. Considerable effort and merit are being put into SMDS as a new public carricr network.

Frame-relay is another form of packet transmission similar to a streamlined X.25 functionality. Frame-relay relies on improved transmission media to climinate some of the expensive overhead involved in transmission crror recovery. It is assumed 
that very few errors will occur and those that do will be handled by end system protocols at the applications.

$\mathrm{SCI}$ is a proposed interface standard for high-performance multiprocessors. It supports a coherent-memory model for a multiprocessor backplanc. The interface defines physical and logical layers. This work is being conducted in an IEEE working group. For an introduction refer 10 Reference 66. Several standards documents can be obtained with an overvicw in Reference 67.

Other framework protocols are sure 10 appear as technology advances. One cxample of a missing requirement is a protocol for combining packet, messagc, and circuit switching as service options to a distributed opcrating system. This is an area for further rescarch. An attempt to fill this necd is being addrassed with the Switched Distributed Data Interface (SDDI). 76

\section{3.t Processors}

Processors are mentioned here to point out two very significant observations within the context of a DSA. First, the impact of parallelism is now fully evident in commercial system architectures. The impact of the Connection Machine's CM-2 and N-Cube's massively parallel machines has been felt at LANL and Sandia National Laboratories in Albuquerque as well as a number of other sites nationwide. Massively parallel machines have demonstrated the capability to solve problems previously thought to be in the realm of the traditional serial supercomputers. At LANL, portability of old code has also been demonstrated to require a surprisingly minimal amount of work. The most important issue is the significant performance that has becn achicved with real problems, such as QCD and three-dimensional hydrocodes.

The second item of note is the end of the era of autonomous supercomputers. Previously, supercomputers drove requirements for network design. In the future, the distributed environment will drive requirements for supcrcomputer architectures. It is now neccssary to have the capability to access networks with a standard interface and provide the software support necessary to cooperate in distributed applications. The high-performance processors of the future will be components of a larger system. The major impact will be on design of system architectures of the future. Special consideration will be necessary for design of the internal backplane and $1 / O$ systems. Failure on this point will likely prove very costly to commercial vendors. 
It is also worth mentioning the potential of clustering workstations for costeffective solutions to large applications. ${ }^{*}$ Such a configuration will provide an easy mechanism to divide the efforts of workstations, as is necessary, and allow small incremental increases in power at minimal cost. Finally, the impact of very different architectures for physical system modeling, such as the CAM-6 77 and iWarp, 59 should not be overlooked. Systems like this take full advantage of parallelism and apply it to physical systems in gencral.

\subsection{Projects and Test Beds}

As stated carlier, five gigabit test beds sponsored by NRI are underway to research high-performance networking, switch design, network adaptors, protocols, system software, system security, performance, optics, and distributed applications. These test beds are entitled Aurora, Blanca, Casa, Vistanet, and Nectar. The Aurora, Blanca, and Casa Test Beds will concentrate on WANs while Vistanet and Nectar are concerned with MANs. Information about these test beds was taken from Reference 5.

\section{5 .1 Aurora}

Members of the Aurora Test Bed include the Massachusetts Institute of Technology (MIT), University of Pennsylvania, Bellcore, and IBM. Collaborators include Bell Atlantic, MCI Telecommunications and Nynex. Their primary investigation, will be in network services. In particular, MIT will focus on network resource control, University of Pennsylvania on distributed virtual memory, Bellcore on protocols and network architecture, and IBM on a joint architecture effort. The network framework proposed uses SONET with the PARIS and SUNSHINE switches. PARIS was mentioned carlicr and SUNSHINE is a self-routing Banyan switch with output queucing and recirculation queues for higher reliability. The protocol used will be ATM. The applications will center around collaborative business effort and virtual worlds.

\section{5 .2 Blanca}

Blanca members include AT\&T Bell Laboratories, Lawrence Berkeley Laboratory, the National Center for Supercomputing Applications, the University of California at Berkelcy, the University of Illinois at Urbana-Champaign, and the University of

* From a talk by Bill Joy of Sun Microsystems, Inc. at Fronticrs of Supcrcomputing II: A National Reassessment, Los Alamos National Laboratory, Los Alamos, New Mexico, August 1990 . 
Wisconsin. Collaborators include Ameritech, Astronautics, Bcll Atlantic, Cray Research, Norlight, and Pacific Bell. The network protocol used in this test bed will also be ATM. The switch will be the Experimental University Network, or XUNET-2, initiated by AT\&T. Other links will utilize HIPPI, FDDI, and DS-3 standards. Applications included in this test bed are multiple remote visualization and control of simulations in atmospheric modeling, radio astronomy imaging, a multimedia digital library, and medical imaging.

\section{1 .5 .3 Casa}

Casa test bed participants include LANL, the California Institute of Technology (CIT), the Jet Propulsion Laboratory, and the San Diego Supcrcomputer Center. Industrial participants include MCI, Pacific Bell, and US West. The emphasis for this test bed is distributed applications in threc areas. They include a tightly coupled chemical reaction dynamics computation, an interactive visualization program in gcophysics with input data from Landsat, scismic and topographic databascs, and a climate modul combining atmosphere and occan models. The network framework will include physical layers using HIPPI and SONET. The transport layer will choose from TCP, VMTP, NETBLT, and Ultra's ISO TP4. System software will be chosen from LINDA, 78 STRAND88, 79 or CIT's Express. 80

\section{$\mathbf{3 . 1 . 5}$ Vistanet}

Vistanet members include Bell South, the Microelectronics Center of North Carolina, the University of North Carolina at Chapel Hill and GTE. Their network is ATM and SONET based with HIPPI network access for supercomputers. The application will be a 3-D interactive imaging program to aid physicians in planning radiation doses for patients.

\section{1 .5 .5 Nectar}

Nectar 22 constitutes the fifth test bed. Members include CMU, the Pittsburgh Supcrcomputing Center, Bell Atlantic, and Bell of Pennsylvania. Their rescarch focuses on high-specd networks. It is a fiber-optic network using a gigabit switch designed at CMU. Protocol processing is done by a CMU's CAB. HIPPI will also be installed on the CAB. System software and protocol issucs are a primary interest in this test bed. Processors will include a Cray YMP and the iWarp also developed by CMU and Intel. 


\section{1 .5 .6 Autenet}

Another project of special note is the Autonet. 81 This is a high-specd, selfconfiguring, switching LAN developed at the Systems Research Center in Palo Alto. The interesting feature of this network is threefold. First, it is based on active switches rather than the passive switching of Ethernet. Secondly, it configures itself into a spanning tree at initialization or upon a link or node failurc. Finally, the addressing and host software has been designed to make Autonet look indistinguishable from an Einernet. This final item is important when considering migration paths of currently installed Ethernet-based networks. Autonet-II will be an implementation using HIPPI as the physical layer protocol. Encryption is also part of their design. It is expected to be implemented in 1991.

\section{5 .7 Multiple Crossbar Network}

A network project associated with HIPPI was started at LANL 3 years ago. This was called the Multiple Crossbar Network (MCN). 14 This amounted to development of a HIPPI-based switch with associated protocol processors. The switch was a standalone unit called the Crossbar Switch (CBS) while the protocol processors were designed and built by DEC and called CBIs. 60 The CBS and CBI combine to form the CrossPoint Star (CP*) switch. Combinations of $\mathrm{CP}^{*}$ form the $\mathrm{MCN}$. A fair amount of testing experience was gained on the CBS. Experience was also gained on the CBI. Connectivity and data transfers were achieved between an IBM 3090 HIPPI, the DEC $\mathrm{CBI}$, and a framebuffer. Later efforts demonstrated successful data transfers on a Cray YMP and Thinking Machines CM-2. A HIPPI tester exists to test HIPPI implementations. It has completed technology transfer channels to Input Output Systems Corporation and is available to industry.

Unfortunatcly, changing prioritics at DEC prompted the cancellation of a second generation CBI. Consequently, LANL has taken what it learned from the collaboration and is now designing and will build an implementation of its own version of the CBI. The CBS success resulted in Network Systems Corporation designing and producing the P8 Switch. Today, this is a HIPPI compatible $8 \times 8$ crossbar switch providing supcrcomputer connectivity. The $\mathrm{MCN}$ is now being realized by installation of $\mathrm{P} 8$ switches and HIPPI hosts in the Casa Test Bed mentioned earlier and the Advanced Computing Laboratory (ACL) at LANL.

Other noteworthy commercial efforts using HIPPI include the Ancor Communications switch being developed in association with Lawrence Livermore National Laboratory (LLNL) and the Ultra Network Technology Corporation's 
UltraNet. The Ancor switch was designed to replace LLNL's graphics capabilitics and is duc for installation and testing in March 1991. UltraNet is available today. It processes protocols at the transport level.

\subsection{Distributed System Software}

Given a gigabit network framework and supporting transfer protocol, the second element of a DSA is the system software. Here again, the ficld is rich in rescarch with no clear winning candidate. Distributed software means different things to different pcople. The spectrum ranges from RPCs to windowing to an all-cncompassing distributed operating system (DOS). This discussion considers no less than the DOS as an essential element of a DSA. Refer to Watson 13 for a description of a future operating system architecture. It also discusses the shortfalls of UNIX in this context. Responsibilitics of a DOS are virtually identical to single-host operating systems. The complexitics are another matter. Issues such as latency, crror control, fault management, resource control, access control, and table coherence are magnificd and complicated by the shecr volume of equipment and interactions of system entities.

Quitc a few distributed systems have been developed and tested extensively. They are simply listed here for reference. Mach 82 was developed at CMU, ISIS 83 at Cornell, Athena 84 at MIT, Express 80 at CIT, Chorus, 85 at the Institut National de Recherche en Informatique et Automatique and V-Kernel 86 at Stanford. LINDA and STRAND88 are also distributed environments available today. The V-Kernel is an example of a DOS with security designed into the system. Examples of commercial systems of interest include IBM's Transparent Computing Facility and Hewlett Packard/Apollos's Network Computing System.

\subsection{Distributed Applications}

The third and final element of the DSA is the set of applications. The requirements of applications affect the first two clements. Given increased use of parallelism, architecture models such as single instruction multiple data (SIMD), multiple instruction multiple data (MIMD), and data flow need to be supported. Reconfigurable architectures such as those represented by the Texas Reconfigurable Array Computer (TRAC), 87 Partitionable SIMD/MIMD (PASM), 88 and Configurable Highly Parallel (CHIP) 89 are highly desirable to allow tailoring of the architccture to the application rather than the reverse. Providing this capability in a gigabit DSA is an extension of scale similar to that of multiprocessors and multicomputers. Another 
characteristic of this architecture is the ability to partition the framework. This gives applications guarantecd resources, limits access to need-to-know users, aids fault isolation and tolcrance, and, most importantly, provides a virtual SIMD or MIMD machine for a number of users. 77 Finally, the ability to connect heterogeneous systems to this DSA allows special purpose machines connectivity as a kind of peripheral device. This appiies to disk farms, frame buffers, special simulators, or whatever is needed. That device then becomes an object with known capabilities to interested users. Combining these systems allows multilevel applications. An example of this is specch recognition with raw data acquisition, data rendering, image display, and expert system analysis done within the context of a single application. 22,90 Most all of these characteristics are applicable to the NTB applications. Consequently, this fits very well into the mission of the NTB as a system simulator of defense technologies.

\subsection{NTB Distributed System Architecture}

The DSA has becn characterized as a metacomputer. Characteristics include 1) a modular, richly connected communication framework of links, switches, and network adaptors; 2) a simple, streamlined framework protocol; 3) a distributed operating system; and 4) an object-oriented directory service for resource management and access control. The cential theme for this architecture is a synergy of processors, communication, managing software, services, user interface, and applications to produce an image of uninterruptible service from a single logical entity available to users of the system.

When considering a DSA, three things come to mind. They are the need for a standard interiace to attached supcrcomputers, the multitude of choices in switching methods and system software, and the obscrvation thai backplanes of hosts and networks from local to wide area extent are virtually identical. The first point is extremcly importani for connectivity. Fortunately, a proposed standard supcrcomputer interface now exists in the form of HIPPI and in the form of SCI in the near future. The second point begs for a structure that will accommodate the experimentation and use of these technologies independent of each other and yet contributing a uniqueness to the system as a whole much as the special purpose processors attached to the system. The last point is relevant to the design of a scamless network backplanc neccssary for distributed computation. It represents quite a change in perspective with interesting implications. A network is no longer a group of autonomous hosts connected by links and switches but clusicrs 
communicating as pecrs. The clusters are devices communicating over an internal cluster backplane. One or more of the devices on each cluster provide intercluster communication. At the final destination, or traditional host, data is delivered to the final device whether it be memory, a frame buffer, or some form of controller such as for a disk.

Rather than discuss the various reasons for building a framework a particular way, a process of building a framework through description and figures will be pursued here. Throughout this process, relevani features of interest will be pointed out to the reader.

\subsection{Hardware Eramework}

Given that HIPPI is a commercially implemented, proposed standard supercomputer interface, it will be used as the link component of the DSA. The switch elcments will be a generalization of the $\mathrm{CP}^{*}$ switch. The switches themselves are not restricted to a HIPPI-based physical layer; however, HIPPI-based switches will be used here for simplicity. Some interface adaptors exist, most notably a VME/HIPPI adaptor card. Interface adaptors are depicted in the logical layout of Figure 3. Sequencers move data into and out of memory, such as the video random access memory (VRAM) in Figure 3 , which may be configured as multiple queucs for efficiency. The Protocol Processor (PP) acts as the intelligent forwarding, or protocol translation, agent. These adaptors are expected to be more then mere translators.

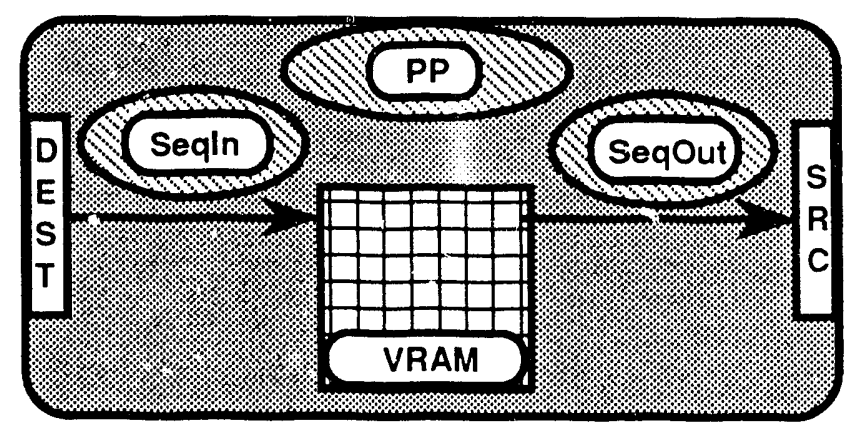

\section{Figure 3. Simple Logical Diagram of an Interface Adaptor.}

They are in fact coprocessors. Their functionality, however, is single purpose. That is to provide an intelligent communication agent at bifurcation points in the IN. To begin the process a short description of HIPPI is in order. 
The signaling for HIPPI is shown in Figure 4. As a simplex point-to-point link, the protocol is straightforward. A physical connection is established with a REQUEST from the source and acknowledgement of a CONNECT by the destination. Transmission of data is signaled as a PACKET. Actual data is transmitted as a BURST. The destination signals that it is READY for a burst of data. Multiple READYs can be sent by the destination. As part of the connection sequence, one word of data may be transmitted with the REQUEST for connect. This is switching information for an intermediate controller or switching mechanism.

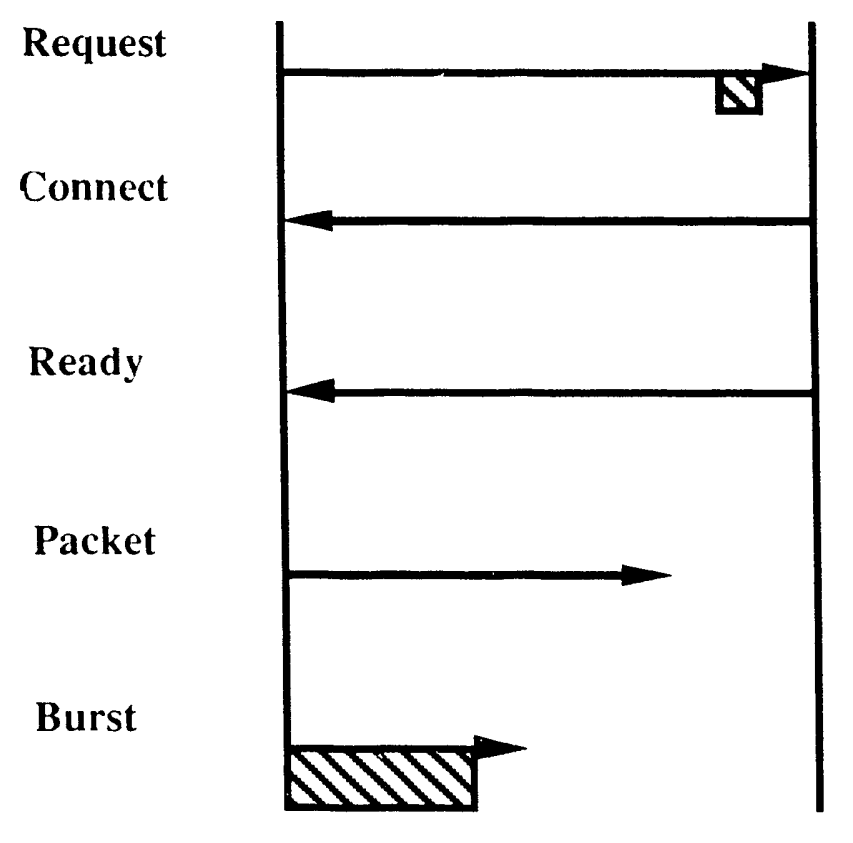

Figure 4. HIPPI Signaling.

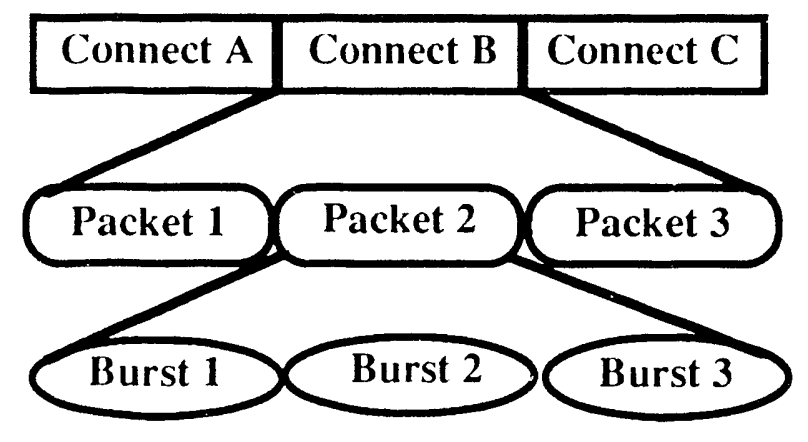

Figure 5. Logical hierarchy of HIPPI structures. 


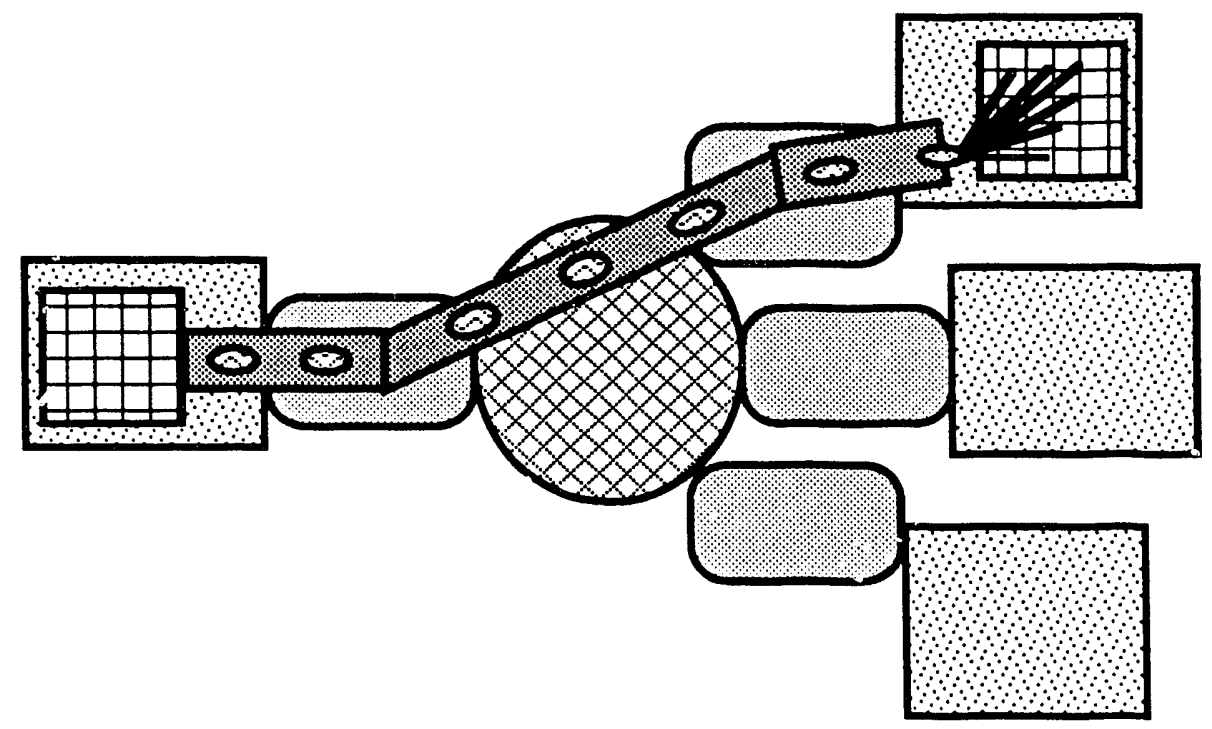

Figure 6. Packets passing over a connection through a switch.

The resulting logical hicrarchy of data structures is shown in Figure 5 . There is no limit to the number of packets within a connection nor the number of bursts within a packet. An illustration of data passing through a switch is depicted in Figure 6, which applics to buffered or bufferless transmissions.

The simplest casc for connectivity immediatcly brings a HIPPI point-to-point link and interface adaptor cards into play as seen in Figure 7. For additional connectivity a crossbar switch can be introduced as depicted in Figure 8. Supcrcomputers, workstations, and device controllers can then be attached using appropriate adaptors to form a simple cluster. Expanding the capacity of the cluster is a matter of connecting crossbars into a multistage network. The number of ports $c a n$ then be

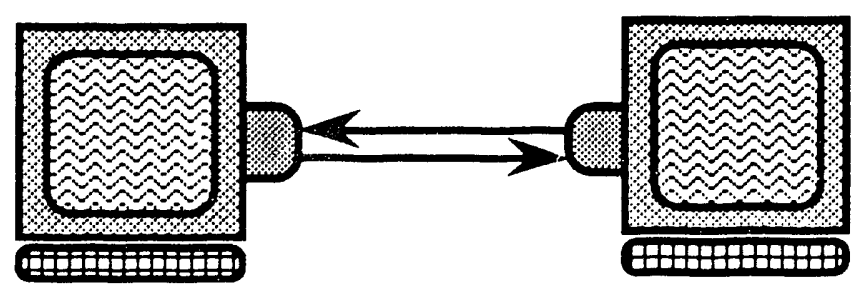

Figure 7. Simple configuration requiring two adaptors and cables. 


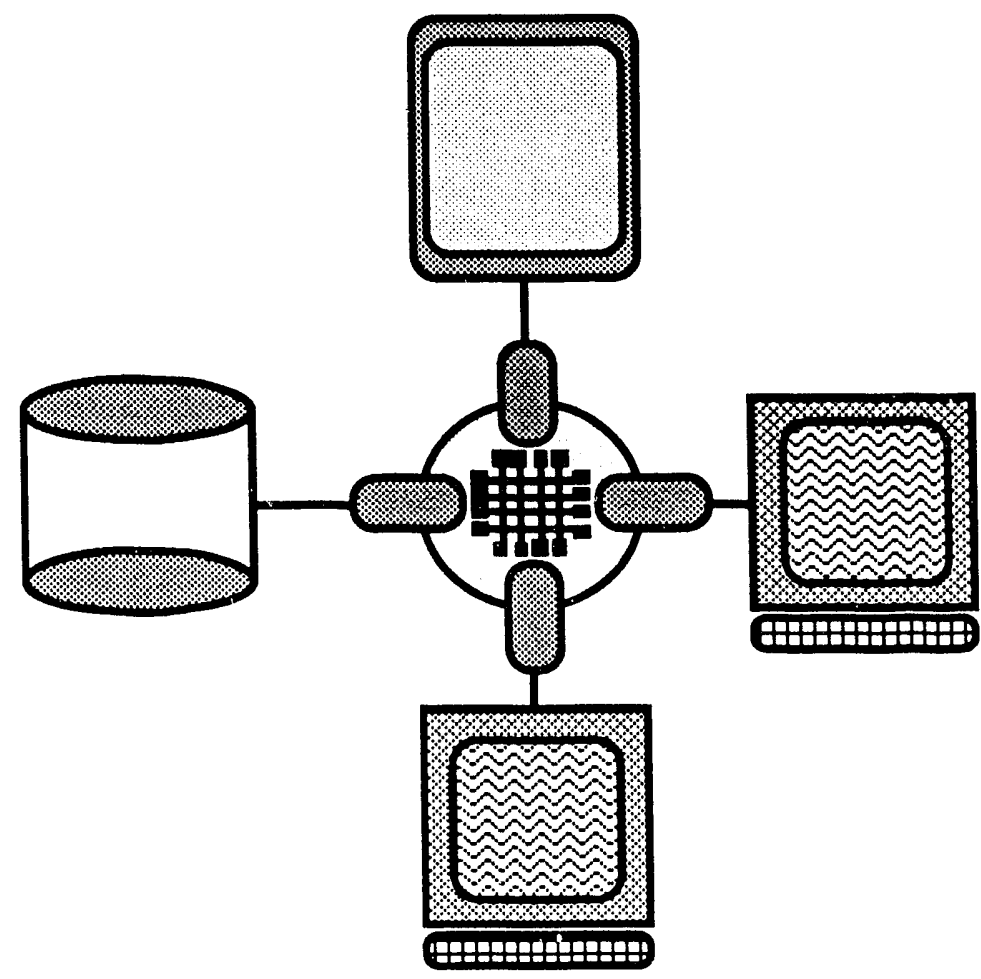

Figure 8. A cluster with a crossbar interconnect.

scaled to suit the need. At this point, a distinction will be made between a host and a node. The purpose is to encourage the image of equivalence between a node and cluster as communicating multiprocessor entities rather than atomic systems like the traditional network host. The difference between a node and cluster is that a node is the final destination for data transfers.

To expand the framework to multiple clusters, communication adaptor cards are added to the cluster. At this point, topology becomes an issue. Many topologies are possible incliding a line, ring, mesh, or more complicated structure such as hypcrcube 91 or n-star. 92,93 It is also possible to have an irregular topology. Ad hoc connectivity, however, is considered unnecessary and, ultimately, unmanageable in a gigabit framework. The potential utility of a regular topology for simplified routing, fault management, and security should not be ignored. For illustrative purposes a hypercube topology has been selected for this discussion. A hypercube of clusters is depicted in Figure 9. Now consider a blown-up vicw of a cluster within this hypercube. Sec Figure 10. There are four intercluster links in this example with a hypcrcube interconnection network within the cluster itself. Node adaptors fill remaining slots of the cluster and provide backplane translations and encapsulation 
if necessary. It is not a requirement that these adaptors be in a single cabinet or in close proximity. Problems may arise when considering the combined requirements of the node and cluster backplanes.

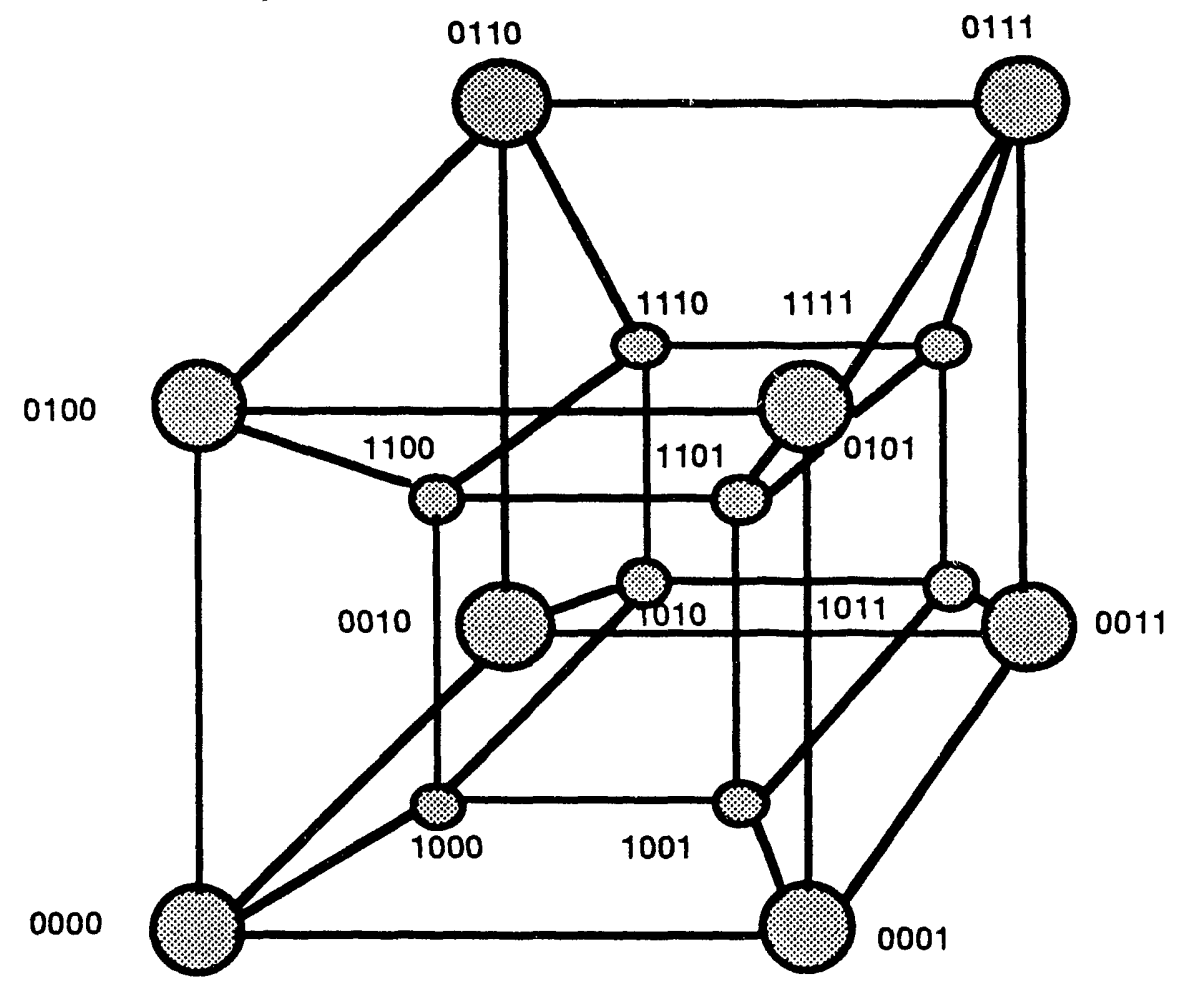

Figure 9. Clusters in a hypercube topology.

Finally, note that the intracluster network is not restricted to crossbars, hypercubes, or even HIPPI. A generalization of cluster INs is possible by building appropriate interface adaptors from HIPPI to other local network or bus architectures. Ethernet or FDDI are cxamples of intracluster INs which might be used. Sec Figures 11 and 12. Packets traversing this type of IN would be encapsulated with the appropriate protocol header. This allows flexibility beyond HIPPI-based networks. The pros and cons of this method will be bricfly discussed in the next section on software.

Figure 13 is an example of the cluster connection to the node. Data arriving at this point is delivered to the appropriate device by the node communications adaptor. Buffering may or may not occur here. If a device is ready or can be readicd in time, the virtual cut-through or wormhole technique will be used and data sent directly on to the final device. A frame buffer is a good example of this. Private memory and disks on the other hand may present a few more complexities, requiring data staging 
before an appropriate controller moves the data to a final destination. Gencrally speaking, a shared memory node architccturc is most appropriate as a final destination, as depicted in the figure, although various message-passing topologies are possible.

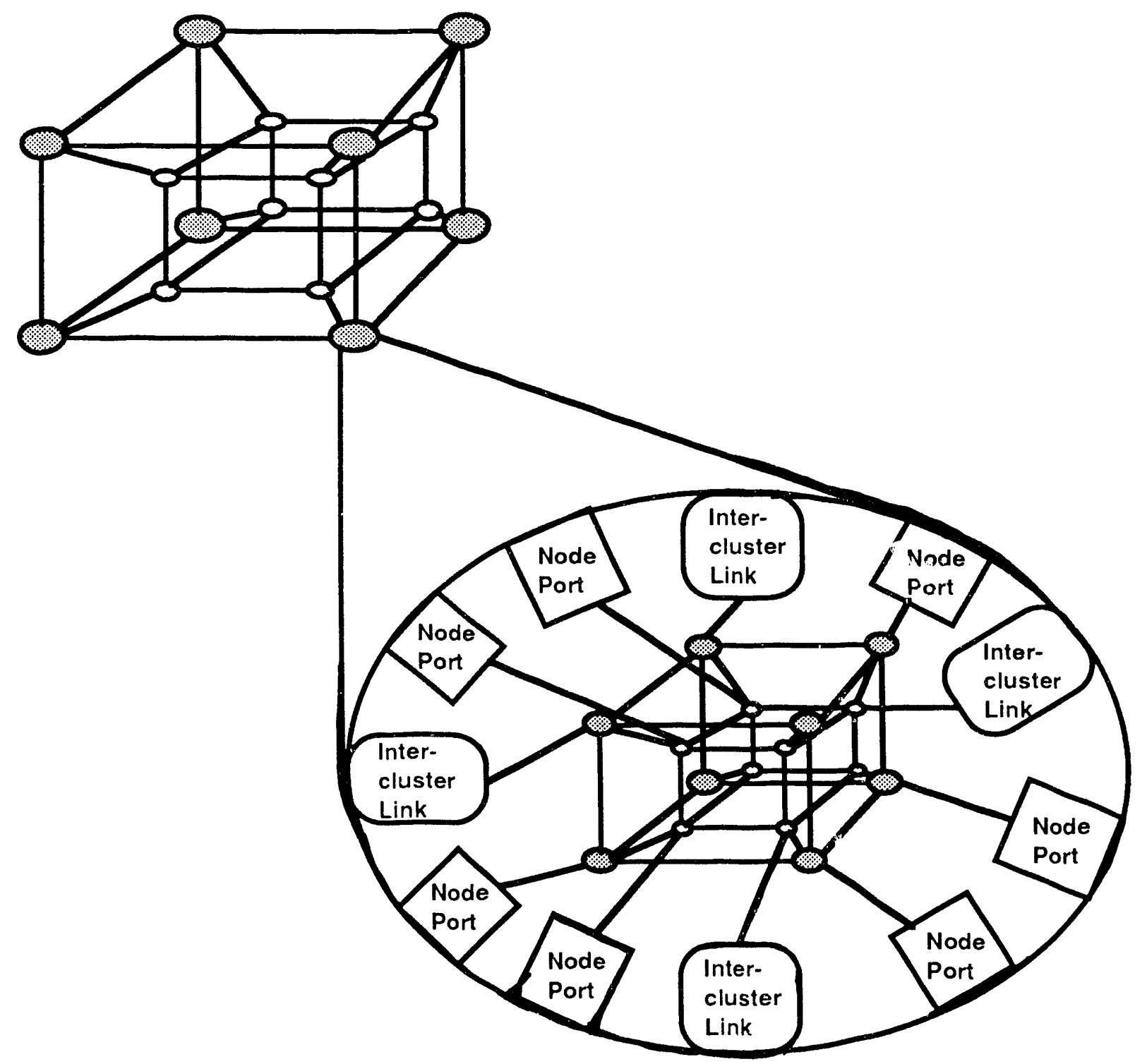

Figure 10. Expanded view of a cluster of the physical framework. 


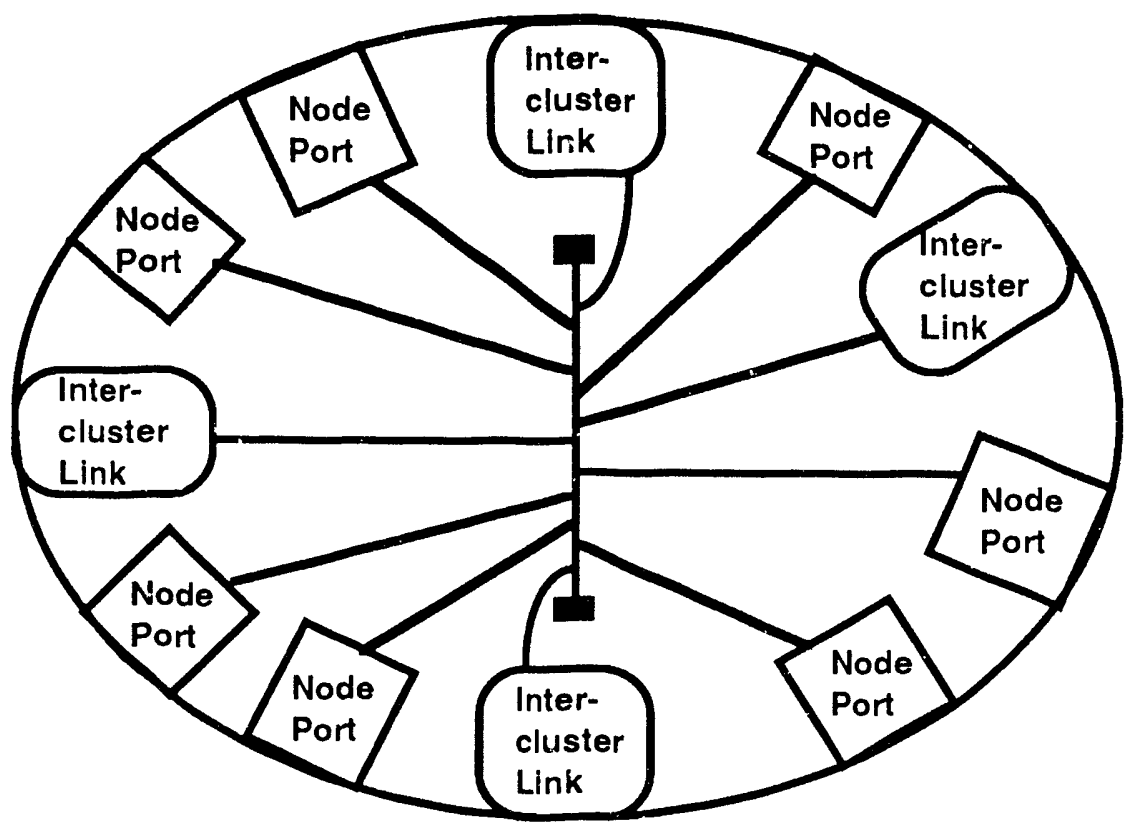

Figure 11. Cluster with Eihernet interior IN.

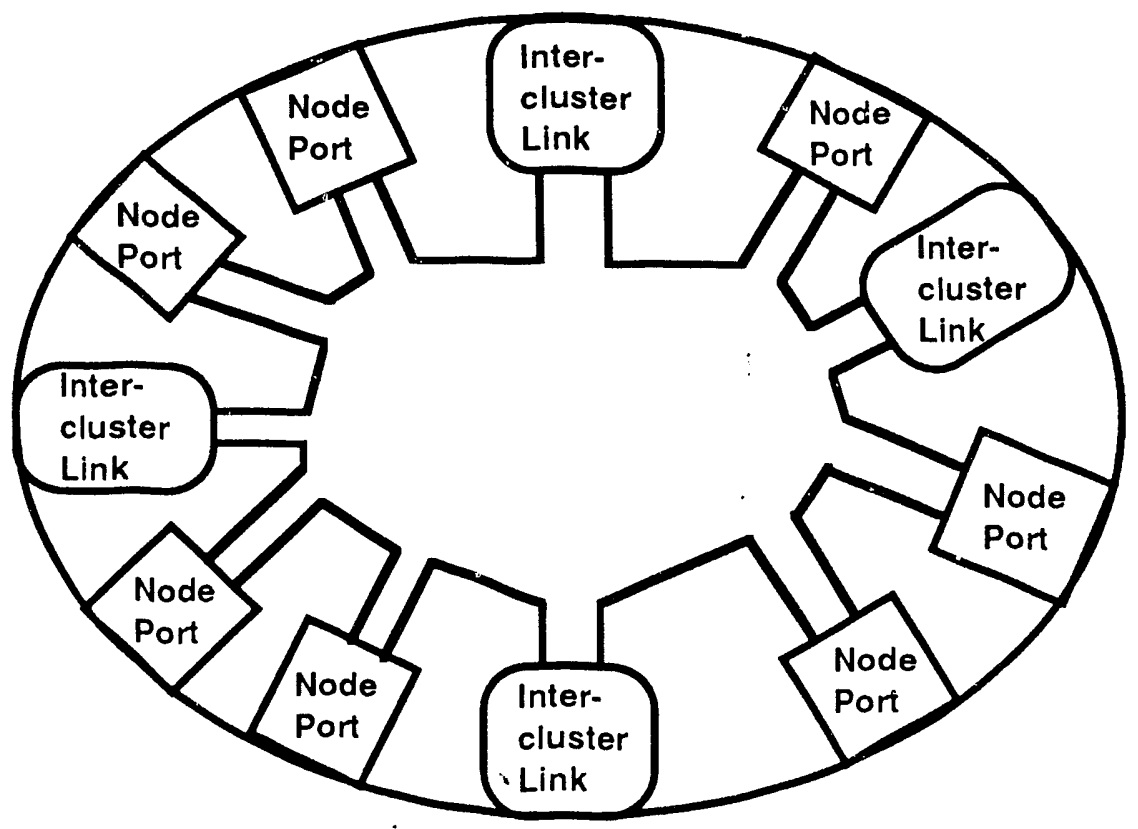

Figure 12. Cluster with FDDI Token Ring interior IN. 


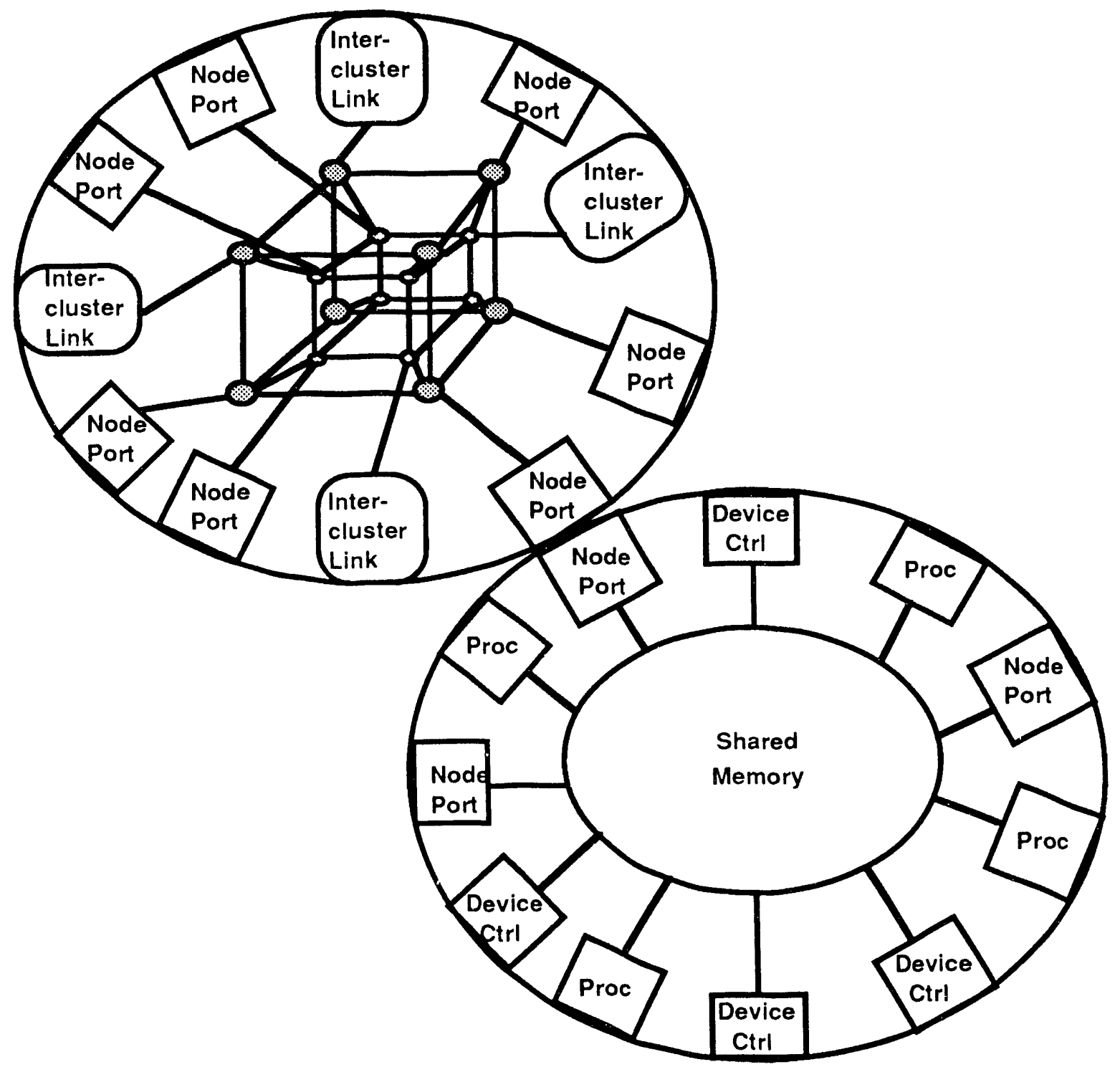

Figure 13. View of a node beyond the communication framework.

\subsection{System Software Support}

\subsubsection{Framework Protocol}

An carly implementation of the DSA would probably consider TCP/IP or ISO's TP4/CLNP as the transport and internet protocols of choice. As new protocols, XTP and VMTP should be given scrious consideration as end-to-end protocols. ATM is a candidate for a framework protocol; however, it is not entircly appropriate since it only provides a packet switching service. XTP was designed as a streamlined VLSI implementation of a fast network protocol and is part of an ANSI standardization effort; however, implementation experience is still needed. VMTP has been designed 
and used with the V-Distributed System. ATM is the protocol of choice by the telecommunications industry and expected to be used over SONET (fiber) networks. These protocols could probably use HIPPI directly; however, at least some form of simple glue protocol would be better to optimize the use of HIPPI services.

No protocol or software implementation currently exists over HIPPI. An carly suite of protocols were specified and implemented as part of the LANL/DEC CBI collaboration.* Although little experience has becn gained nor much experimentation or testing done with protocols over HIPPI, the ANSI/HIPPI Working Group has attempted to specify protocols to run over HIPPI. The HIPPI Framing (HIPPI-FP) and Link Encapsulation (HIPPI-LE) protocols will provide an interim solution until an appropriate framework protocol is developed. The HIPPI-FP and HIPPI-LE protocols are designed to run under the IEEE 802.2 Logical Link Control Protocol, which is the same method used on IEEE LANs. By taking this course of action, considerable software will be saved and porting efforts to HIPPI-based networks minimized. The capability to utilize TCP/IP with or without these intermediate protocols is still an option. Finally, as is evident in the literature, pancls, and workshops, new approaches to high-specd network protocols are being sought. Experimental protocols are also an option for a HIPPI-based network. A simple, effective distributed backplane protocol is possible and is currently being described coincident with the completion of this report. 76

The remainder of the software aspect of the DSA will describe services and characteristics that may or may not be available in an existing protocol. The minimal scrvice of unreliable datagram transmission is all that is required for the overlying system software. This can be provided by TCP/IP over HIPPI. Some of the services described below, however, cannot be provided by TCP/IP.

\section{$\$ 2.1$ Switching Trpes}

Threc types of switched communication have been common practice in data communications. They are 1) circuit switching, 2) packet switching, and 3) message switching. HIPPI is not strictly a circuit-switching mechanism nor strictly a packetor message-switching mechanism. It can provide any and all of these mechanisms to an overlying protocol. This is accomplished by maintaining appropriate signaling over multiple hops of a network. HIPPI is also not restricted to store and forward

\footnotetext{
The specifications, "Protocol Suite for the Multiple Crossbar Network", were written by Randy Hocbelheinrich and Richard Thomsen at Los Alamos National Laboratory.
} 
networks. It can support virtual cut-through and wormhole routing. The diflerence between cutthrough and wormhole routing is in the buffering and responses to blocked paths. 26 Cut-lhrough routing will degrade to a store and forward network when blocked while wormhole routing blocks a message over multiple links and switches. Hot potato, 94 desperation, 95 voluntary misrouting, 96 and derouting 97 all use no buffering and always sclects an ongoing path through the network regardless of whether or not it is the most appropriate path for forwarding data. Experimentation with these types of switching and routing in a HIPPI environment is worthy of consideration. Figure 14 illustrates the possible movement of data through a network when using HIPPI.

\section{2 .12 Phesicil Addressing and Routing}

Addressing in the past has becn cither flat or hicrarchical. Relative addressing can be cither ordered or random. Flat addressing is expensive in terms of hardware cache and look-up overhead when routing because global knowledge of all addresses is necessary. A hicrarchical structure has proven uscful in many areas of human cndeavors. In the case of addressing, it aids routing decision cfficiency and simply breaks the problem of locating nodes down to a manageable scale. Ordered addressing is similar to hicrarchics by limiting the scope of necessary work within a local contcxt. Random addressing requires a global scope. Explicit information about all nodes is necessary to locate a given node. This may be irrelevant on a single broadcast network segment; however, as soon as bridging is required, random addressing has a performance impact duc to learning overhead. Ethernet uses flat, random addressing because addresses are not associated with location as might be expected. Instead, the addresses are associated with an interface which can be moved resulting in an amorphous address space. The result has been a necd for extensive overhead in global table updates, which is a drain on network bandwidth.

Physical addressing in the DSA is hicrarchical and ordered. Both routing hardware and soltware are simplificd with this method. This is the reason for the regular topology. Administrative routing overhead is unnecessary because no lookup tables for the physical routing framework are used. The size of hardware cache for tables is reduced. Most importantly, self-routing techniques are possible. As secn in the literature, much of the current fast packet switches use self-routing techniques. Note that HIPPI does not require a regular topology nor preclude the use of an irregular topology and the consequent table-driven routing techniques. 
Self-routing has advantages because it specifies alternate paths in a permutation or routing tag derived from node addresses. Deadlocks are also preventable by an appropriate sclection of paths. 70 This routing tag is a permutation of possible switch settings at each stage of an IN and is derived from the address of the destination node. Figure 15 is a good illustration for a comparison of Ethernet and a multistage local network (MSLN). Ethernct can rely on broadcast and passive address recognition as its switching mechanism. A switched LAN needs the routing tag for active switching at each stage of the IN. The I-Field in the HIPPI specification is intended to contain this routing tag for cach connection request. In this way, a HIPPI connection can be made over one or more stages of intermediate switches between the source and destination adaptors. This lag is determined at the interface adaptor to each cluster in the network. To an external user, the end result is the appearance of a switched local network similar to Ethernct. This comparison becomes important later when considering migration and standards.

\section{2 .3 Flow and Congestion Control}

Flow and congestion control are subjects of rescarch and interest to many in data communications. In the DSA, traditional methods can be used as a fallback position. This is undesirable because gigabit rates will not tolcrate the traditional methods of window-based flow control and congestion mechanisms such as source quench. Streamlining the flow and congestion control will become necessary. A back pressure flow control mechanism, similar to that used in TYMENET, 21 is possible by appropriate implementation of the HIPPI READY signal. READY signals act on a linkby-link basis; however, given message switching with cut-through or wormhole routing, these signals can be propagated back to the source through interface adaptors. When using HIPPI, a problem does exist over long lines. The source is only required to account for up to 64 READYs at a time. The result is cither underutilization of long links or overflow. Two remedics are possible. One is explicit flow control in the overlying protocol and the other is to enhance the HIPPI specification at some later date. At any rate, flow control is aided by determining the propagation delay per link and allocating buffers for that delay. In this way, the physical parameters of a link are considered in order to cmulate fluid flow. Minimizing the buffers limits the clasticity in the system and results in more timely fecdback to the source. 


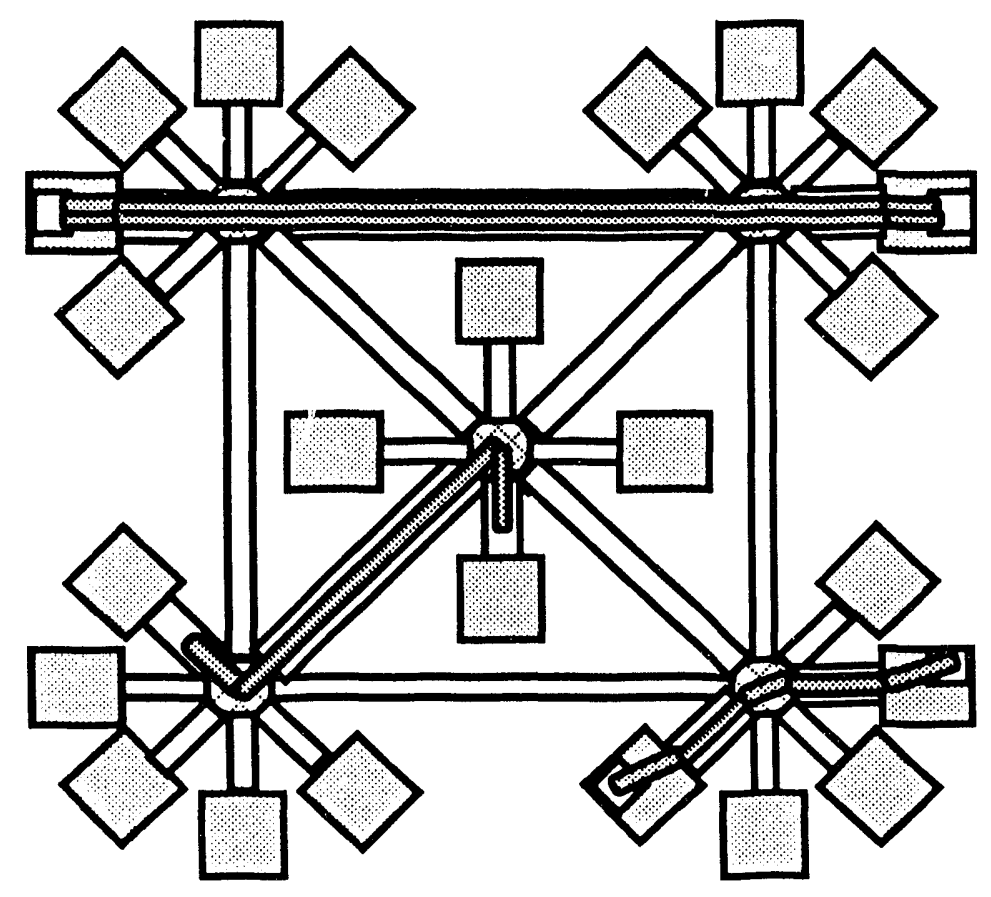

Figure 14. Multiple clusters with data transfers in progress.
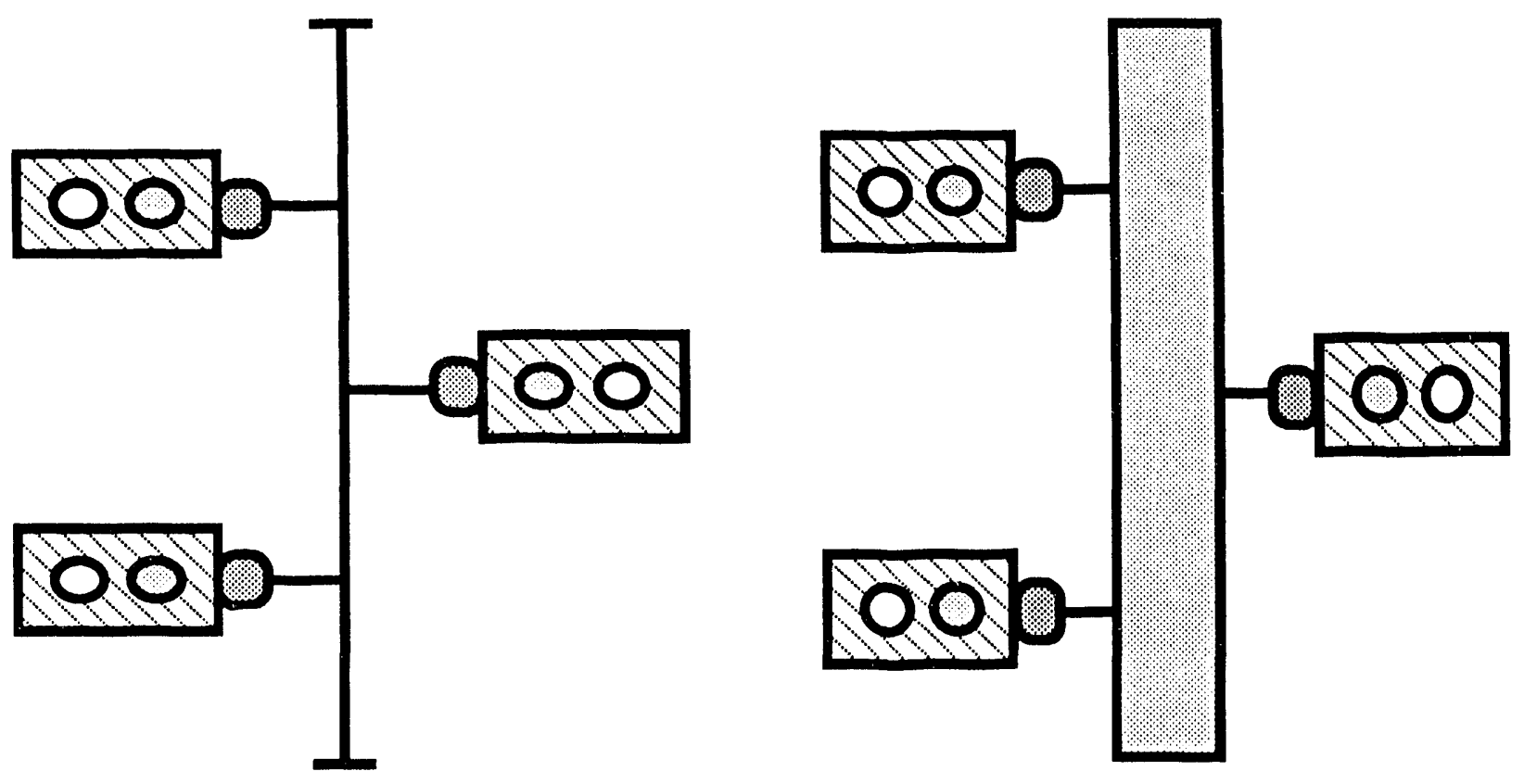

Figure 15. Comparison of Ethernet vs. switched LAN. 
For internal congestion, an aging mechanism associated with messages and wormhole routing is possible to produce a global backpressure mechanism to limit entry of 100 much data into the network. The aging mechanism is expected to prevent livelock and insure that data leaves the network. * Both of these methods are attempts to mimic the bchavior of physical systems in order to control flow and congestion. As requirements grow, redundant links, or extra stages, to the network may be needed for chronic congestion. Multiple, or redundant links, are groups of physical lines with the same logical port number. The intermediate controller selects a frec physical link for any given logical port connection request providing additional bandwidth and multiplexing over these lines where necded. External congestion is handled by multiple links both into and out of the nodes.

\subsubsection{Logical Addressing and Partitioning}

Logical addressing provides mobility for entitics such as servers, users, special purpose processors, or whatever object becomes a part of the network. It provides a mapping to multiple physical addresses. Consequently, the flexibility to be independent of geographic location as well as a multihoming capability exists for multiple links to an object. It has been shown how physical addresses benefit routing. In a similar way, logical addressing benefits the manipulation of groups of objects with identical, or mutually cxclusive, capabilitics. For cxample, uscrs of a particular organization or project can obtain a suitably registered logical address that associates them as members of a set, or group, independent of their respective locations. Separation is established from other users. Refer to Figure 16. This represents two different logical groups, each with threc logical to physical associations to the communication framework. For actual communication, logical addresses for objects are queried, cached, and translated to establish current location and transfer data across the network. The logical address space can be taken one step further by mapping it to a regular abstract topology. This would result in a logical structure that is similar to the structure of the physical addresses. Consecuently, the logical and physical address spaces and associations could look like Figure 17. Note that it is not necessary that the logical and physical topologies are identical. The most uscful characteristic for the logical structure is the use of masks in comparisons at the source and destination node adaptors to determine the right for members of two

\footnotetext{
* Private communication with and unpublished report of Vance Faber, C-3, Los Alamos National Laboratory.
} 


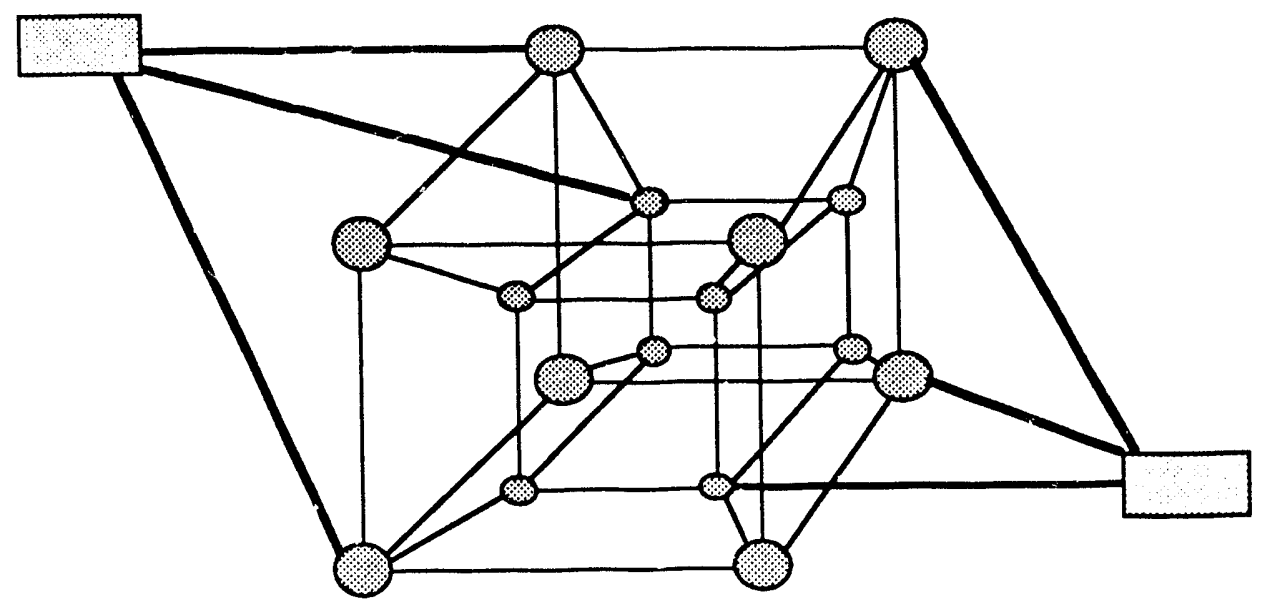

Figure 16. Two logical groups, connected physically at six points.

logical addresses to communicate. Appropriate sclections of logical addresses and masks will provide necd-to-know separation, partitioning, and hicrarchical access to appropriate members of a given logical address. Figure 18 demonstrates partitioning of logical adciresses into four groups with four possible members in cach group. Larger 64-bit addresses are expected to be used for logical aodressing. Logical addresses can be based on organization, function, or capabilitics such as reid/write access to objects or information. The result is a partitioned regular topology for the logical address space. An cxample of a four-partition hypercube of clusters is in Figure 19. At this point, the security dominance rclationship for reading down and writing up described in Reference 3 is a natural consequence of the architecture.

\section{$4,2,1.5$ Error Control}

\subsection{Data Transmission Errors}

Data transmission error rates on HIPPI have been reported to be very low. Currently HIPPI uses a longitudinal and vertical redundancy check (LRC/VRC) error detection scheme. This results in possible undetected crrors. A 64-bit cyclic redundancy check (CRC) has been proposed by DEC to replace the LRC/VRC. An optical version of HIPPI would use forward crror correction (FEC). Again, gigabit rates will not be tolerant of traditional retransmission schemes for transmission cror recovery. For DSA, an crror-correcting code is proposed, and crror detection and notification of the packet and fault location within cach packet is also required. 


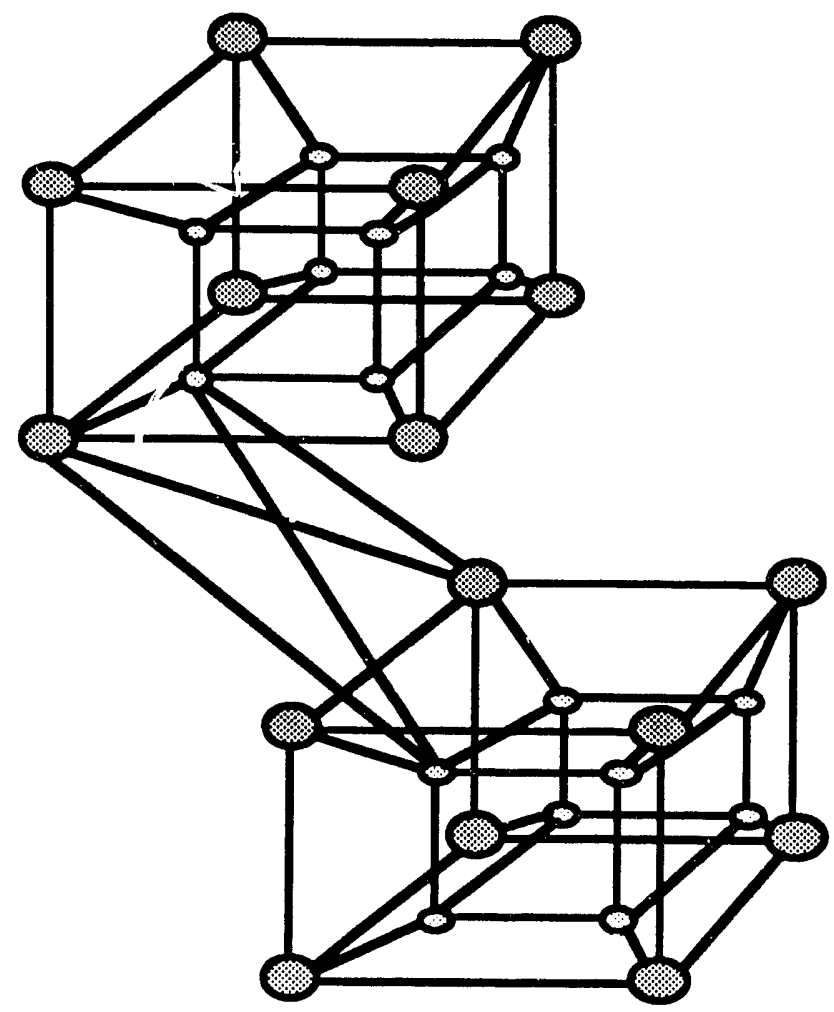

Figure 17. Logical address space connected to physical address space.

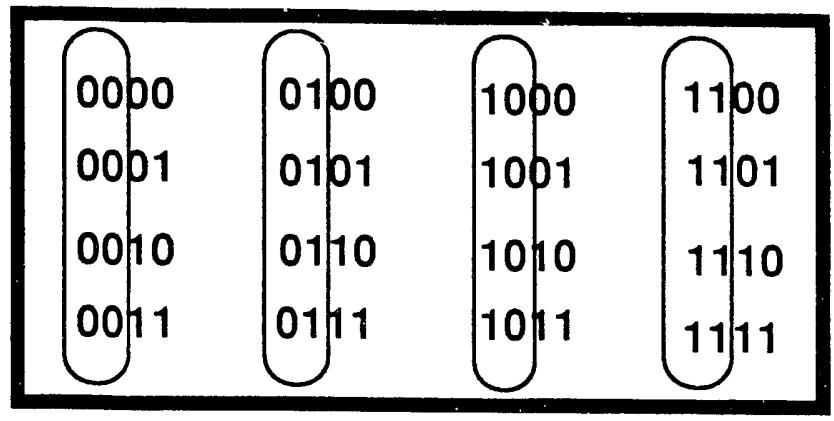

Figure 18. Sixteen logical addresses partitioned into four groups. 


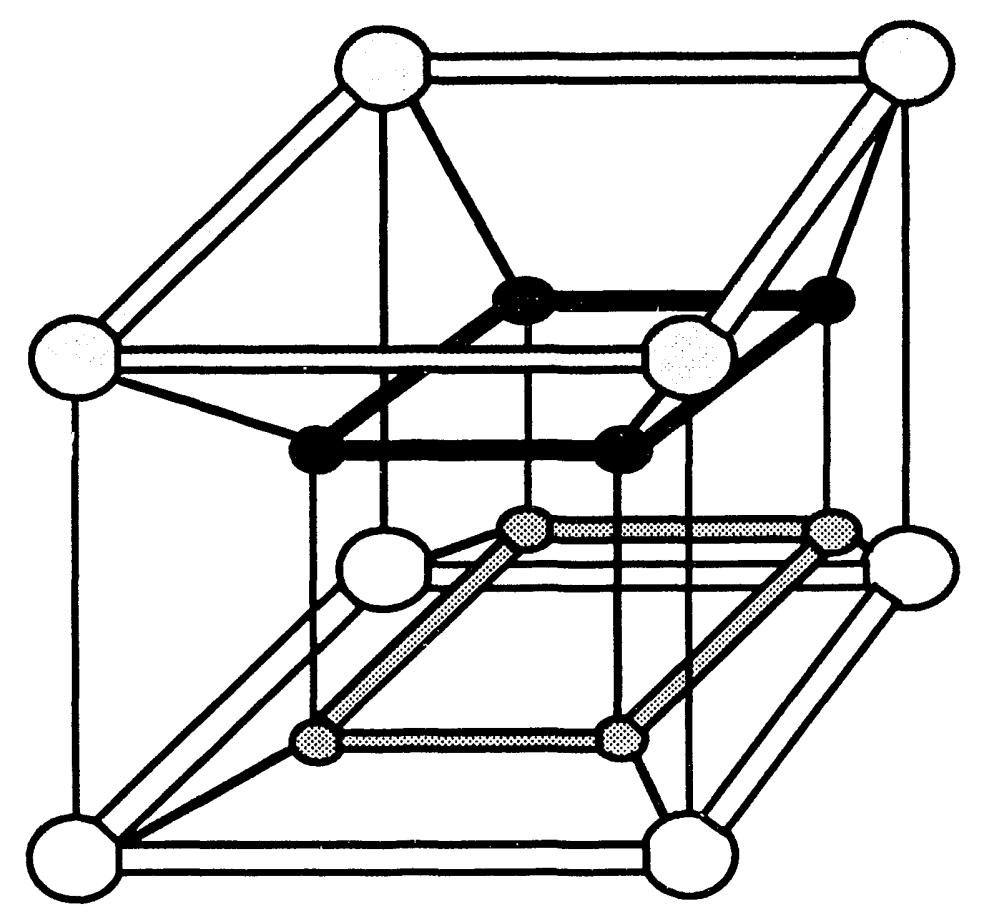

Figure 19. Logical address space partitioned into four groups.

\subsection{Link and Node Falilures}

Fault location is extremely important as a proactive management mechanism for the system. This will be accomplished by the crror notification scheme above and the monitoring network described below. Another characteristic of error detection is a requirement that crror information must be propagated through a node or adaptor 10 determine failures within that node or adaptor as opposed to a link failure. Before a failure is found and corrected, other data must be redirected and continue moving. Consequently, alternate paths are required and a method to switch to them is implicit in self-routing.

\subsubsection{Heterogeneous Cluster Protocols}

The advantage of having hetcrogeneous non-HIPPI INs in clusters is the ability 10 use various technologics already in existence and experiment with new technologics. Dissimilar addressing and routing do not present problems since all that is required is a cache of external address to internal address translaticns on the local cluster alone. These translations can be obtained within the local environment and do not require global knowledge of all addresses. The relation of how to route to a distant node is implicit in regular topology addressing. The disadvantage is that the IN will 
not necessarily provide all the services that the protocol over HIPPI provides. This results in the well-known interworking problem that must be dealt with when disparate services are used over a logical link. For example, HIPPI packets may be longer than an internal clusters packet size and may require packet fragmentation. Data arriving on the other side of the cluster may no longer be in sequence. The protocol over HIPPI will then need to provide for packet reassembly and sequencing. The option to include an internet protocol such as IP on the adaptors does exist. In any case, one can keep a homogencous HIPPI network similar to current extended LANs to minimize interworking problems.

\subsection{Operating System Software}

This section will not deal with the operating system software explicitly, except to say that the purpose of any underlying distributed backplane protocol and framework was intended to support the necds of the system software. With the cstablishment of the framework, the opcrating system has the foundation necessary to communicate with any object of the system it finds necessary and provide the scrviccs it has to uscrs requesting them. Instcad, a short discussion of the scrvices available to users follows. These services are provided by a framework protocol on bchalf of the system.

Services provided by the system include resource management, allocation, and access control. This includes fair access to scarce resources. Resources include cxplicit objects, such as a visualization frame buffer or a particular processor, for cxample. Other resources include implicit system elements such as network bandwidth and clear paths through the network. Explicit resources can be handled by allocation and queucing mechanisms. The implicit resources need a scheme for fair usage of bandwidth and paths. HIPPI and an appropriate framework protocol can provide this.

Communication services have traditionally used a connection-oricnted or connectionless service for pairwise transmissions. This translates to one- or two-way circuit switching and packet or message switching. Circuits provide dedicated paths but waste bandwidth and block paths for other transmissions. They can cren partition the network without sufficient redundancy in internal network links and multihomed nodes. Packet switching allows an optimal interlcaving of data by many transmissions to minimize blocking and optimize utilization of network bandwidth. As stated carlicr, HIPPI can provide a spectrum of transmissions from packet-tocircuit switched data by appropriate use of signaling and intermediate-switching 
technology. Recall Figure 14. That figure shows a two-way circuit and two examples of message switching using wormhole routing. In one case, the message tail is shown leaving the source before the header has arrived at the destination. The second case shows a message spanning the length of the distance from source to destination. The third case shows a connection maintained for greater than a round trip delay. These cases demonstrate the simple continuum of data transfer service alluded to carlicr. Coupled with system software and administration of the network, the HIPPI capability can be used to provide all of these services within a single nelwork.

This is accomplished as follows. Explicit resources or objects such as visualizalion platforms have permissible services, such as circuit switching, associated with them. When a user needs this resource the visualization object is either requested or reserved. The DOS queues or schedules this request. The user may or may not be blocked from further work while waiting for access to the object. As the request is serviced, the user is given the go-ahead to connect to the resourec or it is reserved for a later time. In any case, upon execution, the framework protocol will have a service type, such as circuit switching, attached to the request and use HIPPI appropriately to set up the necessary circuit. A service, such as retrieval of a filc or E-mail, would only be allowed to use the message-switching service. In the case of a massive simulation, muliple objects could be reserved for a particular lime. These reservations need not tic up an entire machinc. With multiple links into a node, multiple sessions could be time shared with periodic message traffic on one link and dedicated traffic on the other link. Using this method will provide, and yet limit, the use of services to a level that will not deteriorate the system to the detriment of other users. To summarize: 1) objects have scrvice capabilitics attached to them, 2) a user requests access to an object, 3) the DOS queues, allocates, and grants access, and 4) the system then controls explicit use of the service that is provided by HIPPI. This method may also be expanded to include requirements for reliability as well as throughput and delay.

Given packel switching over the backplane, an end-to-end transport protocol is necessary to insure sequential data. One possible alternative mechanism is to provide a header and trailer on each packel with pointers relative 10 other packets in the same message. At the destination, a linked list is formed that is updated and completed as data arrives. Upon completion, missing data is requested, cither crrors are corrected or selectively retransmitted (that were specified in the trailer), and the data is delivered to the end object. In delivering this data, either the data is stripped of headers and trailers and moved to the final location or the end object can be passed 
the head of the list and access the data indirectly much as is done in virtual paging systems now. It is, in fact, expected that the packets will be distributed virtual memory pages or cache blocks of data with associated system parameters and pointers resident in the block.

\section{3 .1 Directory Service}

As stated earlier, the directory service acts as the clcaringhouse for locations and capabilities of objects in the system. An object can be a device, user, server, or application. These objects can be members of a logical set of objects, such as members of a project. Functions performed by the directory include registration of an object to establish its existence, authentication of users requesting 10 enter the system, controlling access to objects by uscrs, and providing information about objects to authorized entities. The directory would also be closely ticd to key distribution, event logging, auditing and accounting systems. The most difficult function would be maintaining eache coherence for logical address caches on outlying nodes.

\section{$\$ 3.2$ Monitoring Service}

The monitoring service is intended to provide a real time display of the data traffic as well as load and status of links and nodes in the system. This is accomplished by an orthogonal network made up of high-speed serial links out of each interface adaptor to a collection site. A prespecified set of information is sent out on a periodic basis by interface adaptors. This information is written to a grid of parameters. These parameters are used by a cellular automata machine to computc and display data movement as well as link and node status. Given buffering, it is conceivable that buffer levels could also be monitored and color displayed on a screen. This provides a qualitative fecl for load, hot spots, and link or node failures.

\subsection{Accounting}

Accounting for scrvices takes advantage of the integration of coherent distributed opcrating system structures, user to resource allocation mechanisms, and the message stream characteristic of the transport framework. Specifically, upon allocation of a resource by a user, costs are accrued as data passes the origin of communication from the head to tail of a message or request 10 hangup of a connection. Type of service factors affecting cost are also considered at the origin. These factors include the system effort to insure reliability, or security. the length of lime a path is locked due to large images or unused bandwidth, and initial priority 
assigned to a message or connection. Consequently this provides the mechanism to impose varying costs due 10 dynamic usage patterns and changes in policy. Some semblance of management and conservation of scarce resources is then possible.

\subsection{Security}

The security policy is implicit in the architecture of the system with incorporation of logical addressing and capability-based access through a directory service. The logical addressing and associated capabilities tic closely with the COIs discussed in Reference 3. These security policies can easily be enhanced in this architecture by a cooperative directory and key distribution service. The architccture provides checks of these COIs in interface adaptor hardware and software upon entrance 10 and exit from the network backplane. Encryption provides protection on a session basis. Encryption at gigabit rates is a fairly new cndeavor. This level of protection will provide separation, although the inclusion of an MLS system is also a requirement. MLS is out of the scope of this report.

\subsection{Migration Path}

Migrating from the current NTB to the DSA described above is fairly straightforward. The nature of the equipment allows a phased, modular approach to migration. Migration would progress in three major phases. Phase 1 is development and testing of equipment and protocols. Phase 2 is replacement of mainframc LANs with clusters and the implementation of intercluster links and adaptors. Phase 3 is attachment of workstation LANs to clusters that are in turn linked to mainframe clusters. Phase 3 also includes implementation of long-haul links to RAS clusters. Pieces of this migration paih follow development of the modules and hicrarchy of the hardware framework described in the previous section. The major pieces are 1) interface implementation on the hosts, 2) software (drivers and protocols) development, 3) point-to-point link check-out including long- and short-haul links, 4) switch test and checkout, 5) individual Ethernet replacement for mainframes with an intermediate gateway replacing appropriate bridges, 6) intercluster adaptors, 7) directory and monitor service implementations, and 8) a distributed operating system implementation.

As an example of NTB topology, the hypercube pictured carlicr would partition such that the NTB domain would be divided into eight RAS regions with a cluster assigned to each region. Connections to the RASs would be with HIPPI/SONET links. Each RAS SPO within a region would connect local LANs or nodes to one or more links 
of the RAS regional cluster. The internal cube of the hypercube would correspond to NTF clusters. The four upper NTF clusters would be assigned as red partition clusters while the lower four would be black partition clusters. Each cluster is similar to an Ethernet as seen in Figure 1. Intercluster links and adaptors correspond to bridges. That completes the physical framework. See Figure 20. The logical framework would be superimposed over the physical framework and is almost entircly a software issue that includes a framework protocol and overlying system software.

\section{To summarize:}

1. Implement host HIPPI inierface implementations.

2. Develop, test, and install software drivers and protocols.

3. Test and install point-to-point links, both short and long.

4. Test and install a cluster.

5. Test and install an intercluster adaptor.

6. Test and implement a directory server.

7. Test and implement a monitor server.

8. Rescarch, test, and install distributed operating system software.

A few added items are worth noting. There is no requirement to use a hypercube topology. The n-star is another excellent choice of topology for the framework. Recall that each cluster is not restricted to any particular topology or number of ports. Individual links need to be installed both localiy and long haul.

Interface cards into the internal bus of the specific systems are necessary. Vendor support is available for the interface implementations and drivers. Other itcms include the HIPPI/SONET interface and gigabit encryption. Efforts are currently underway to produce HIPPI/SONET links. At least one design and forthcoming implementation is known for gigabit cncryption at this time.

The software requires the bulk of the effort of the migration. The first step involves implementation of a simple link protocol over HIPPI betwecn two workstations. The second step will implement TCP/IP over HIPPI. Finally, an application can be implemented during Steps 1 and 2. Initially, the directory server can be simulated with appropriate static logical-to-physical address translation tables. Applications can be developed throughout the migration although it may mean interim throwaway code development as the migration progresses. 


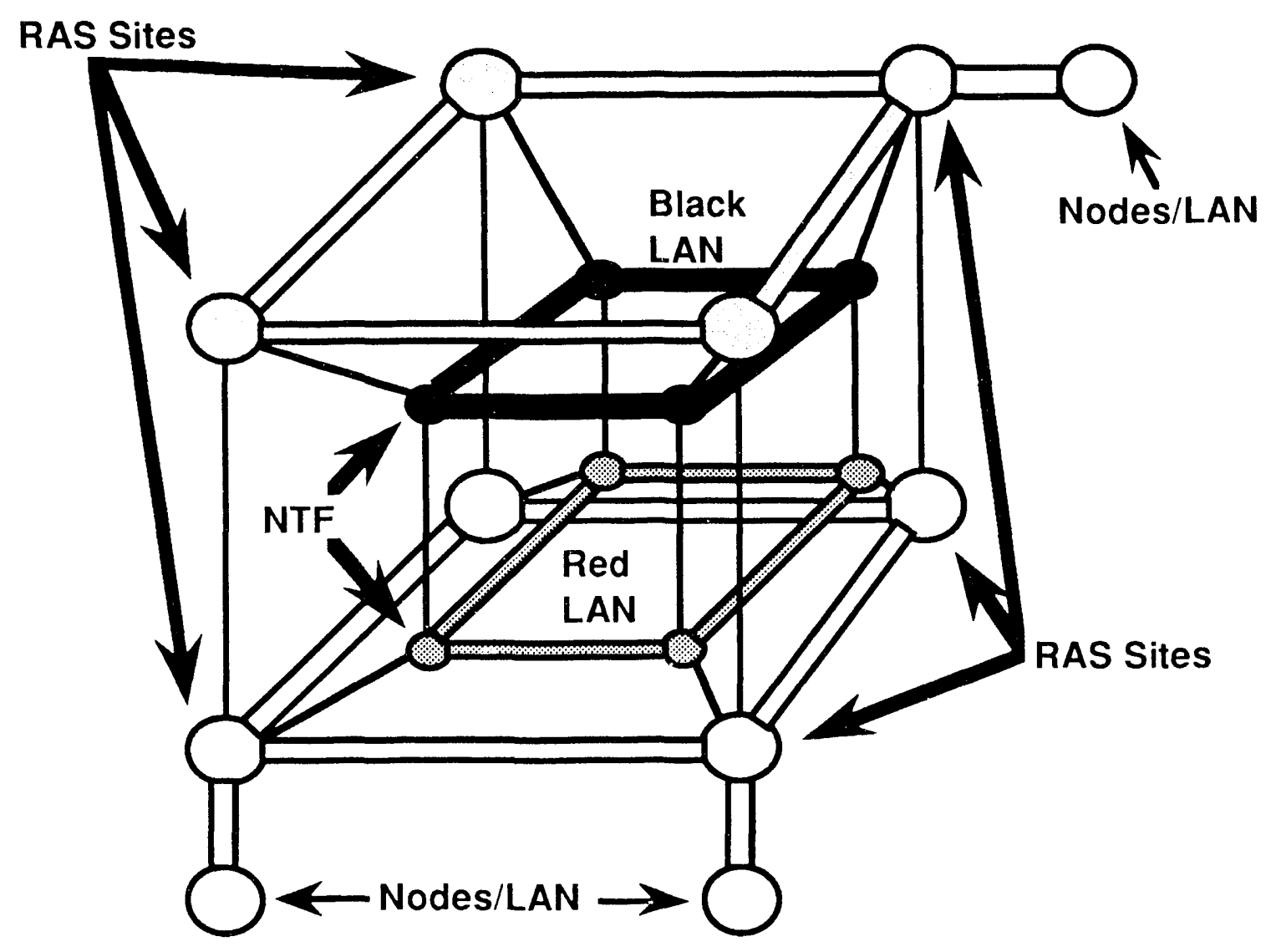

Figure 20. Example NTB DSA.

\subsection{Research Initiatives}

The rescarch effort parallels the migration effort. At each stage of the migration, a certain amount of experience needs to have been gained with equipment and software prototypes or implementations. Some similar efforts are ongoing elsewhere; collaborative efforts are possible and strongly cucouraged. Research initiatives are necessary in three arcas. They are 1) design and development of interface adaptor cards for mainframes, workstations, and controllers, 2) protocol implementations between HIPPI and the transport level such as TCP/IP, and 3) hardware link technology development for a serial fiber implementation of HIPPI, a HIPPI/SONET interface, and transparent gigabit-rate security cncryption units for insertion on the link.

A four-year project is proposed. The first year would deliver an implementation of TCP/IP over HIPPI between two workstations or a workstation and a framebuffer. Applications scrved would be filc and image transfer. This establishes connectivity and the potential for useful work. The second year would deliver a cluster of 
workstations and a frame buffer using the previous implementation communicating over a HIPPI crossbar switch. This would test the exccution of multiple applications exccuting and device contention. In addition, framework and alternative transport protocols would be explored and tested. The third year would deliver intercluster communication and an initial directory service. Distributed operating systems would also be explored and tested. The fourth year would be devoted to implementation of a distributed operating system with associated directory and visual monitoring services. This is just a general overvicw of a set of rescarch initiatives needed for the full architecture described in this report. A modified architecture would require less ambitious efforts. An example would be development of single mainframe or workstation clusters.

\subsection{Summary}

I began by describing the mission of the NTB as a distributed simulation test bed of heterogeneous defense technologics interacting over a global extent. A description of the current movement of computing technology toward unification into a distributed framework environment was presented. The timely creation of the former, with the potential and momentum of the latter, provided the basis for a target NTB architecture for the near future. A modular and progressive migration path, with associaled research initiatives, will work hand-in-hand toward achievement of that goal.

\subsection{Conclusion}

The mission requirements of the NTB provide the impetus to contribute to development of a computing technology central to the revolution and evolution of computing for the next generation at the dawn of the twenty-first century. The NTB provides the forum, opportunity, and focus for a national initiative to produce a real system beneficial, directly and indirectly, to a great many aspects of scientific and enginecring endeavors.

\section{REFERENCES}

[1] T.S. Kuhn, Structure of Scientific Revolutions, Univ. of Chicago Press, Chicago, III., 1970.

[2] Martin Marietta Corporation, "System Description Document for the National Test Bed," NTB-242/442-006, National Test Bed Program, Falcon AFB, CO., January 1990. 
[3] P.A. Bicknell, J.A. Gunter, and S.W. Hansen, "NTB INFOSEC Security Strategy," MITRE Working Report, WP-6962, MITRE, Colorado Springs, CO., October 1989.

[4] Harold J. Raveche, Duncan H. Lawrie, and Alvin M. Despain, "A National Computing Initiative," Report of the Society for Industrial and Applied Mathematics (SIAM), 1987.

[5] Gigabit Working Group, B. Leiner, Editor, "Critical Issues in High Bandwidth Networking," Technical Report RFC 1077, Defense Advanced Research Projects Agency, November 1988.

[6] Workshop Report, C. Partridge, Editor, "Internet Research Steering Group Workshop on Very-High-Speed Networks," Technical Report RFC 1152, Stanford University, April 1990.

[7] "Report of the Par.el on Large Scale Computing in Science and Engineering," Peter Lax, Chairman, Sponsored by the US Department of Defense and the National Science Foundation, in cooperation with the Department of Energy and the National Aeronautics and Space Administration, Washington, D.C., December 26, 1982.

[8] Marcel Bardon and Kent Curtis, "A National Computing Environment for Academic Research." NSF Working Group on Computers for Research, National Science Foundation, July 1983.

[9] Corporation for National Research Initiatives, "Proceedings of the First Gigabit Test Bed Workshop," Compiled by Karen L. Bowers, Corporation for National Research Initiatives, 1895 Preston White Drive, Suite 100, Reston, Virginia 22091, January 1990.

[10] Leonard Kleinrock, "Distributed Systems," Communications of the ACM 28(11), 1200 1213, November 1985.

[11] Andrew S. Tannenbaum and Robert Van Renesse, "Distributed Operating Systems," Computing Surveys, Vol. 17, No. 4, December 1985.

[12] Richard W. Watson and John G. Fletcher, "An Architecture for Support of Network Operating System Services," Computer Networks 4(1980) 33-49.

[13] Richard W. Watson, "The Architecture of Future Operating Systems" UCRL-99896 Lawrence Livermore National Laboratory, Livermore, CA., November 1, 1988. 
[14] Randy Hoebelheinrich and Richard Thomsen, "Multiple Crossbar Network: Integrated Supercomputer Framework," Proceedings of Supercomputing '89, Reno, Nevada, November 1989.

[15] David R. Cheriton, "UIO: A Uniform I/O System Interface for Distributed Systems," ACM Transactions on Computer Systems, Vol. 5, No. 1, February 1987.

[16] J.H. Saltzer, D.P. Reed, and D.D. Clark, "End-To-End Arguments in System Design," ACM Transactions on Computer Systems, Vol. 2, No. 4, November 1984.

[17] K.K. Ramakrishnan and R. Jain, "A Binary Feedback Scheme for Congestion Avoidance in Computer Networks with a Connectionless Network Layer," Proceedings of Communications Architectures and Protocols, Sigcomm 88, Stowe, VT, August 1988.

[18] W. Daniel Hillis, The Connection Machine, The MIT Press, Cambridge, MA, 1985.

[19] Tommaso Toffoli and Norman Margolus, Celluar Automata Machines: A New Environment for Modeling, The MIT Press, Cambridge, MA, 1987.

[20] Roy Maxion, "Emergent Behavior of a Fault Management System in a Network Community" PhysicaD, Vol. 42, Nos. 1-3, 1990. Reprinted in Proceedings of the Ninth Annual International Conference on Emergent Computation, Los Alamos, May 1989.

[21] La Roy W. Tymes, "Routing and Flow Control in TYMNET," IEEE Transactions on Communications, Vol., Com-29, No. 4, April 1981.

[22] E. A. Arnould, F. J. Bitz, E. C. Cooper, H.T. Kung, R.D. Sansom, and P.A. Steenkiste, "The Design of Nectar: A Network Backplane for Heterogeneous Multicomputers," Proceedings of the Third International Conference on Architectural Support for Programming Languages and Operating Systems (ASPLOS III), Boston, Massachusetts, April 1989.

[23] Van Jacobson, "Congestion Avoidance and Control," Computer Communications Review 18(4), August 1988.

[24] David Cheriton, "Distributed Operating Systems on Gigabit Networks," Internet Research Steering Group Workshop on Very-High Speed Networks, Technical Report RFC 1152, Defense Advanced Research Projects Agency, April 1990. 
[25] George S. Almasi and Allan Gottlieb, Highly Parallel Computing, The Benjamin/Cummings Publishing Company, Inc., 1989.

[26] William C. Athas and Charles L. Seitz, "Multicomputers: Message-Passing Concurrent Computers," Computer 21(8), 9-24, August 1988.

[27] Daniel A. Reed and Richard M. Fujimoto, Multicomputer Networks: Message Based Parallel Processing, The MIT Press, Cambridge, MA., 1987.

[28] H. Kanakia and D. Cheriton, "The VMP Network Adaptor Board (NAB): High-Performance Network Communication for Multiprocessors," Computer Communications Review 18(4), August 1988.

[29] T. Y. Feng, "A Survey of Interconnection Networks," Computer 14(12), 12-27, December 1981.

[30] Krishnan Padmanabhan and Duncan H. Lawrie, "A Class of Redundant Path Multistage Interconnection Networks," IEEE Transactions on Computers, Vol. C-32, No. 12, December 1983.

[31] Howard Jay Siegel, Interconnection Networks for Large-Scale Parallel Processing, Theory and Case Studies, 2nd Edition, McGraw-Hill Publishing Company, 1990.

[32] George B. Adams III, Dharma P. Aqrawal and Howard Jay Siegel, "A Survey and Comparison of Fault-Tolerant Multistage Interconnection Networks," Computer, Vol. 20, No. 6, pp. 14-27, June 1987.

[33] Hamid Ahmadi and Wolfgang E. Denzel, "A Survey of Modern High-Performance Switching Techniques," IEEE Journal of Selected Areas in Communications, Vol. 7, No. 7, pp. 1091-1103, September 1989.

[34] Fouad A. Tobagi, "Fast Packet Switch Architectures For Broadband Integrated Services Digital Networks," Proceedings of the IEEE, Vol. 78, No. 1, pp. 133-167, January 1990. 
[35] A. S. Krishnakumar and Krishan Sabnani, "VLSI Implementations of Communication Protocols- A Survey," IEEE Journal on Selected Areas in Communications, Vol. 7, No. 7, pp. 1082-1090, September 1989.

[36] H. Scott Hinton, "Architectural Considerations for Photonic Switching Networks," IEEE Journal on Selected Areas in Communications, Vol. 6, No. 7, pp. 1209-1226, August 1988.

[37] "High-Performance Parallel Interface Mechanical, Electrical, and Signaling Protocol Requirements," Don Tolmie Editor, American National Standards Institute, X3T9/88-127 X3T9.3/88-023, Rev. 7.2 .

[38] Mauricio Arango, David Gelernter, Hussein Badr and Arthur J. Bernstein, "Staged Circuit Switching for Network Computers," Computer Communication Review, Vol. 13, No. 2, February 1983.

[39] "XTP Protocol Definition Revision 3.4", Protocol Engines, Incorporated, 1900 State Street, Santa Barbara California 93101, 1989.

[40] A. Huang and S. Knauer, "Starlite: A Wideband Digital Switch," Procéedings of GLOBECOM'84, Atlanta, GA, December 1984, pp. 121-125.

[41] Jonathan S. Turner, "Design of a Broadcast Packet Switching Network," IEEE Transactions on Communications, Vol. 36, No. 6, June 1988.

[42] Mark J. Karol, Michael G. Hluchyj and Samuel P. Morgan, "Input Versus Output Queueing on a Space-Division Packet Switch," IEEE Transactions on Communications, Vol. C-35, No. 12, December 1987.

[43] Y. S. Yeh, M. G. Hluchyj and A. S. Acampora, "The Knockout Switch: A Simple, Modular Architecture for High-Performance Packet Switching," IEEE Journal on Selected Areas of Communication, Vol. SAC-5, pp. 1274, 1283, October 1987.

[44] H. Ahmadi, "A High-Performance Switch Fabric for Integrated Circuit and Packet Switching," Proceedings of INFOCOM'88, New Orleans, LA, March 1988. 
[45] Gary S. Delp, "The Architecture and Implementation of Memnet: a High-Speed SharedMemory Computer Communication Network," Computer Communication Review, Vol.18, No.4, pp. 165-174, August 1988.

[46] Brett D. Fleisch, "Distributed Shared Memory in a Loosely Coupled Distributed System," Computer Communication Review, Vol.17, No. 5, pp. 317-327, August 1987.

[47] R. Folmar, "Distributed Memory Network: An 8 Gigabit Fiber Optic Tightly Coupled System," Proceedings of the National Aerospace Electronics Conference, Dayton Convention Center, May 20-24, 1985.

[48] M. Devault, J. Cochennec and M. Servel, "The Prelude ATD Experiment: Assessments and Future Prospects," IEEE Journal on Selected Areas in Communications, Vol. 6, No. 9, pp. 1528 1537, December 1988.

[49] Loring Worbel, "NASA Gets Memory-Based Network", Electronic Engineering Times, p. 33, April 23,1990.

[50] T. Takeuchi, T. Yamaguchi, H. Niwa, H. Suzuki, and S. Yayano, "Synchronous Composite Packet Switching-A Switching Architecture for Broadband ISDN," IEEE Journal on Selected Areas in Communications, Vol. SAC-5, No. 8., pp. 1365-1376, October 1987.

[51] H. Suzuki, et al. "Output-Buffer Switch Architecture for Asynchronous Transfer Mode," Proceedings of the International Conference on Communications, Boston, MA, June 1989.

[52] I.S. Gopal, I. Cidon, and H. Meleis, "Paris: An Approach to Integrated Private Networks," Proceedings International Conference on Communications, '87, Seattle, WA, June 1987.

[53] T.N. Mudge, J.P. Hayes, and D.C. Winsor, "Multiple Bus Architectures," Computer, Vol. 20, No. 6, pp. 42-48, June 1987.

[54] A. Varma, A.A. Sawchuk, B.K. Jenkins, and C.S. Raghavendra, "Optical Crossbar Networks," Computer, Vol. 20, No. 6, pp. 50-60, June 1987. 
[55] A.A. Sawchuk, B.K. Jenkins, C.S. Raghavendra, and A. Varma, "Optical Interconnection Networks," IEEE International Conference on Parallel Processing, pp. 388-392, August 2023, 1985:

[56] J.E. Midwinter and P.W. Smith Editors, "Photonic Switching," IEEE Journal on Selected Areas in Communications, Vol. E, No. \%, pp. 1033-1034, August 1988.

[57] Eric Nussbaum, "Communication Network Needs and Technologies- A Place for Photonic Switching ?," IEEE Journal on Selected Areas in Communications, Vol. 6, No. 7, pp. 10361043, August 1988.

[58] Anthony S. Acampora and Mark J. Karol, "An Overview of Lightwave Packet Networks", IEEE Network, Vol. 3, No. 1, pp. 29-41, January 1989.

[59] S. Borkar, R. Cohn, G. Cox, S. Gleason, T. Gross, H.T.Kung, M. Lam, B. Moore, C. Peterson, J. Pieper, L. Rankin, P.ذ.i seng, J. Sutton, J. Urbanski, and J. Webb, "iWarp: An Integrated Solution to High-Speed Parallel Computing", Proceedings of Supercomputing '88, Orlando, Florida, November 14-18, 1988.

[60] William F. Hedberg, "Multiple Crossbar Network: The Crossbar Interface", Proceedings of the 14th Local Computer Network Conference, Minneapolis, MN. October 1989.

[61] D.R. Cheriton, "VMTP: A Versatile Message Transaction Protocol", Technical Report RFC 1045, Defense Advanced Research Projects Agency, February 1988.

[62] David D. Clark, Mark L. Lambert, and Lixia Zhang, "NE:BLT: A Bulk Data Trar'sfer Protocol," Technical Report RFC 969, Defense Advanced Research Projects Agency, December 1985.

[63] Ken-ichi Sato, Satoru Ohta and Ikuo Takizawa, "Bro?d-Band ATM Network Architecture Based on Virtual Paths," IEEE Transactions on Communications, Vol. 38, No. 8, August 1990.

[64] F. Dix, M. Kelly, and R. Klessig, "Access to a Public Switched Multi-Megabit Data Service Offering", Computer Communication Review, Vol. 20, No. 3, pp. 46-61, July 1990.

[65] K.J. Chen, K.K.Y. Ho, and V.R. Saksena. "Analysis and Design of a Highly Reliable Transport Architecture for ISDN Frame-Relay Networks", IEEE Journal on Selected Areas In Communications, Vol. 7, No. 8, pp. 1231-1242, October 1989. 
[66] E. H. Kristiansen, K. Alnaes, B. O. Bakka and M. Jenssen, "Scalable Coherent Interface", Eurobus Conference Proceedings, Munich, Germany, May 9-10, 1989.

[67] "SCI (Scalable Coherent Interface) An Overview", IEEE:P1596-15, Doc 171-1, Part 1 D0.59, Working Group P1596, Sponsored by the Standards Subcommittee of the Technical Committee on Microprocessors and Microcomputers of the IEEE Computer Society, February 1990.

[68] David R. Cheriton, "Sirpent: A High-Performance Internetworking Approach", Computer Communication Review, Vol. 19, No. 4, pp. 158-169, September 1989.

[69] Zygmunt Haas and David R. Cheriton, "A Case for Packet Switching in High-Performance Wide-Area Networks", Computer Communication Review, Vol.17, No.5, pp.402-409, August 1987.

[70] K. Sabnani and A. Netravali, "A High Speed Transport Protocol for Datagram/Virtual Circuit Networks", Computer Communication Review, Vol. 19, No. 4, pp. 146-157, September 1989.

[71] Parviz Kermani and Leonard Kleinrock, "Virtual Cut-Through: A New Computer Communication Switching Technique", Computer Networks, Vol.3, pp. 267-286,1979.

[72] William J. Dally and Charles L. Seitz, "Deadlock-Free Message Routing in Multiprocessor Interconnection Networks", IEEE Transactions on Computers, Vol. C-36, No. 5, May 1987.

[73] D. Nassimi and S. Sahni, "A Self-Routing Benes Network and Parallel Permutation Algorithms", IEEE Transactions on Computers, Vol. C-30, pp. 332-340, May 1981.

[74] Willy Zwaenepoel, "Protocols For Large Data Transfers Over Local Networks", Computer Communication Review, Vol. 15, No. 4, September 1985.

[75] Christopher A. Kent and Jeffrey C. Mogul, "Fragmentation Considered Harmful", Computer Communication Review, Vol. 17, No. 5, pp. 390-401, August 1988.

[76] Randy L. Hoebelheinrich, "A Switched Distributed Data Interface for a Distributed System Architecture", LA-UR 90-2109, Los Alamos National Laboratory, Los Alamos, New Mexico, June 19, 1990. 
[77] Tommaso Toffoli, "CAM: A High-Periormance Cellular-Automaton Machine", PhysicaD, Vol.10D, Nos. 1, pp. 117-127, 1983.

[78] Gelernter, D., "Generative Communication in LINDA", Technical Report YALEU/DCS/RR294, Yale University Report, No'ember 1983.

[79] I.T. Foster and S. Taylor, STRAND: New Concepts in Parallel Programming, PrenticeHall, Englewood Cliffs, NJ, 1989.

[80] ParaSoft Corporation, "An Overview of the Express System", Express Fortran User's Guide Version 3, ParaSoft Corporation, 2500, E.Foothill Blvd. Pasadena, CA 91107, 1988.

[81] M. D. Schroeder, A.D. Birrell, M.Burrows, H.Murray, R.M.Needham, T.L.Rodeheffer, E.H.Satterthwaite, and C.P.Thacker, "Autonet: A High-Speed, Self-Configuring Local Area Network Using Point-To-Point Links", Report 59, DEC Systems Research Center, Palo Alto, CA. 1990.

[82] M. Accetta, R.Baron, W.Bolosky, D.Golub, R.Rashid, A.Tevanian, and M.Young, "Mach: A new kernel foundation for UNIX development", Proceedings of Summer Usenix, July 1986.

[83] K. Birman, R. Cooper, T. Joseph, K. Marzullo, M. Makpangou, K. Kane, F. Schmuck, and M. Wood, "The ISIS System Manual, Version 2.0", The ISIS Project, Cornell University, Ithaca, New York, April 1990.

[84] E. Balkavich, S.R. Lerman, and R.P. Parmelee, "Computing in Higher Education: The Athena Experience", Communications of the ACM , Vol. 28, No.11, November 1985.

[85] "Overview of the Chorus Distributed Operating System", Computing Systems, The Journal of the Usenix Association, Volume 1, Number 4, 1988.

[86] David R. Cheriton, "The V Distributed System", Communications of the ACM, Vol. 31, No. 3, March 1988.

[87] M.C. Sejnowski, E.T.Upchurch, R.N.Kapur, D.P.S. Charlu, and G.J.Lipovski, "An Overview of the Texas Reconfigurable Array Processor", Proceedings AFIPS NCC (1980):631-641, published by American Federation of Information Processing Societies Inc. National Computer Conference. 
[88] H.J. Siegel, L. J. Siegel, F. C. Kemmerer, P. T. Mueller Jr., H.E. Smalley Jr., and S.D. Smith, "PASM: A Partitionable SIMD/MIMD System for Image Processing and Pattern Recognition", IEEE Transactions on Computers, Vol. C-30, No. 12, pp. 934-947, December 1981.

[89] L. Snyder, "An Introduction to the Configurable Highly Parallel Computer", Computer, Vol. 15, No. 1, pp. 47-56, January 1982.

[90] Y. Bengio, R. Cardin, R. De Mori, and E. Merlo, "Programmable Execution of MultiLayered Networks for Automatic Speech Recognition", Communications of the ACM, Vol. 32, No. 2, February 1989.

[91] H. J. Siegel and R.J. McMillen, "The Multistage Cube: A Versatile Interconnection Network", Computer, Vol. 14, No. 12, pp. 65-76, December 1981.

[92] Sheldon B. Akers, Dov Harel, and Balakrishnan Krishnamurthy, "The Star Graph: An Attractive Alternative to the n-Cube", 1987 International Conference on Parallel Processing, pp. 393-400, August 17,21, 1987.

[93] V. Faber and James W. Moore, "High-Degree Low-Diameter Interconnection Networks with Vertex Symmetry: The Directed Case," LA-UR-88-1051, Los Alamos National Laboratory, March 1988.

[94] Burton J. Smith, "Architecture and Applications of the HEP Computer System", Proceedings of the 1981 SPIE Conference 298, pp. 241-248, August 25-28, 1981, San Diego, $\mathrm{CA}$, published by the International Society for Optical Engineering, Bellingham, Washington.

[95] Frank Pittelli and David Smitley, "Analysis of a 3-d Toroidal Network for a Shared Memory Architecture", Proceedings of Supercomputing '88, Orlando, Florida, November 1988.

[96] John Ngai and Charles L. Seitz, "A Framework for Adaptive Routing in Multicomputer Networks," Proceedings of the Symposium on Parallel Algorithms and Architectures, Santa Fe, New Mexico, June 1989.

[97] S. Konstantinidou and L. Snyder, "The Chaos Router: A practical application of randomization in network routing", Proceedings of the Symposium on Parallel Algorithms and Architectures, Crete, July 1990. 

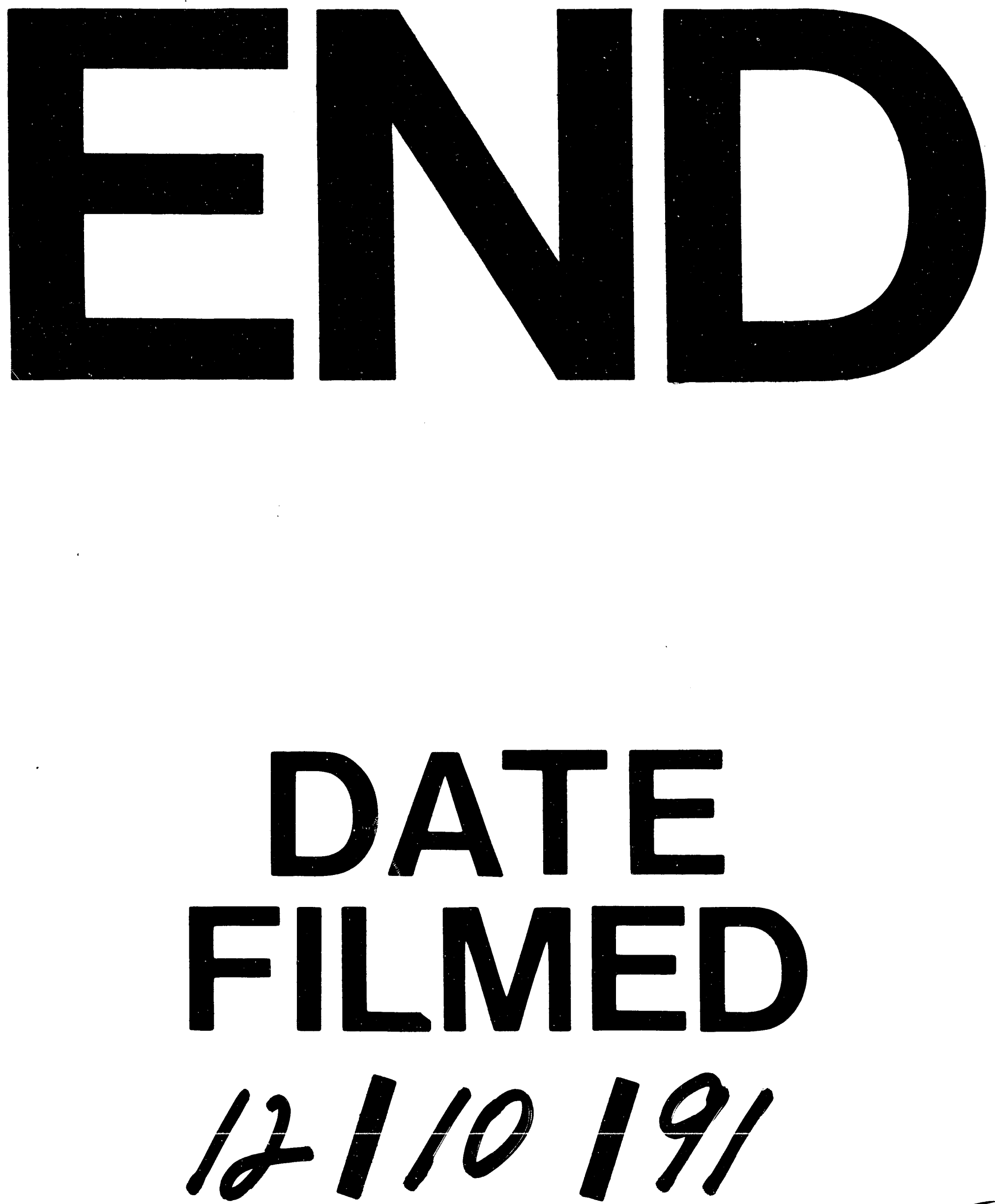

I 
$\cdot$ 